
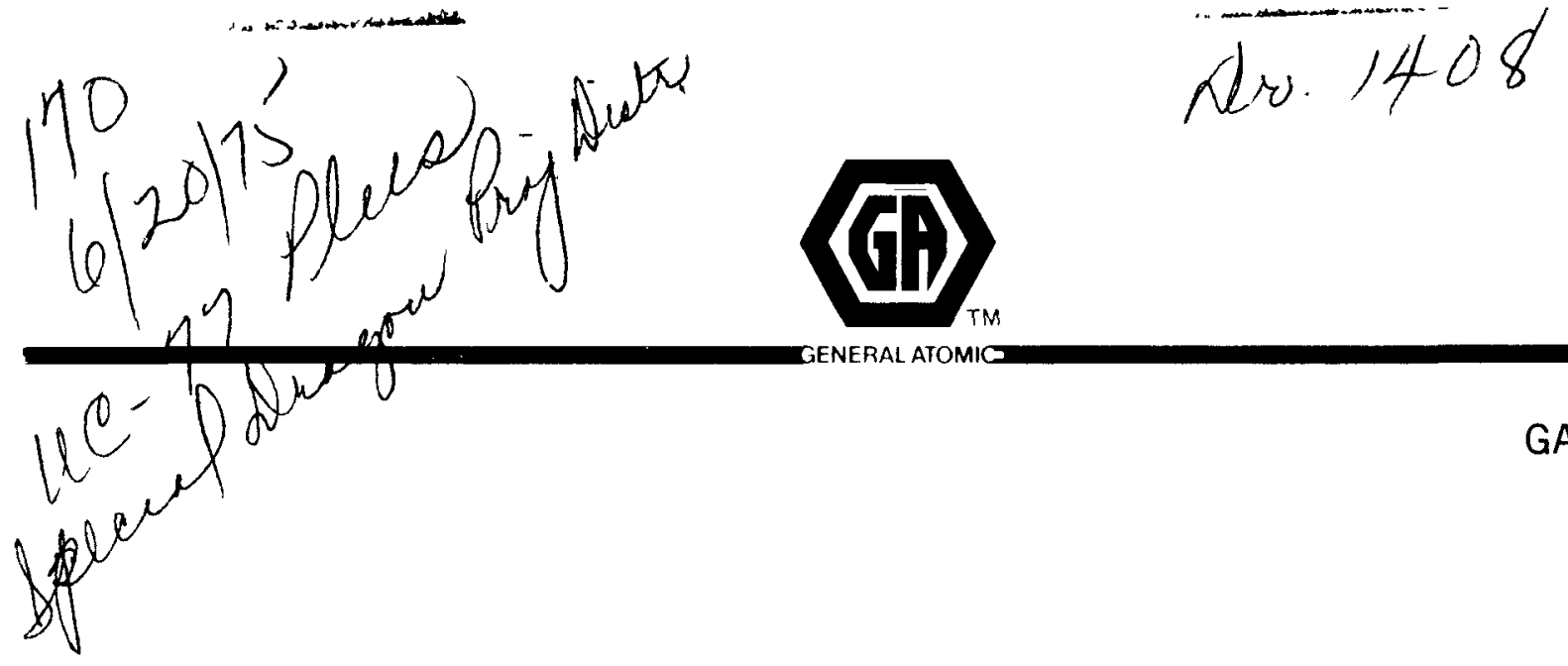

\title{
PLANNING GUIDE FOR VALIDATION OF FISSION PRODUCT TRANSPORT CODES
}

\author{
by \\ D. D. Jensen \\ M. J. Haire \\ J. E. Baldassare \\ D. L. Hanson
}
Work supported in part under
Contract AT(04-3)-167
Project Agreement No. 17
for the

San Francisco Operations Office

U.S. Energy Research and Development Administration

DATE PUBLISHED - APRIL 15, 1975 


\section{NOTICE}

I his report was prepared as an account of work sponsored by the I nited States Government Nesther the United States nor the Unted States Fnergy Research and Development Adininistration, now any of theil employees, nor any of their contractors subcontidetors, or their employees, makes any wat ranty, express or implied or assumes any legal habilitv on responsibility for the accuracy, completeness of usefulness of any information apparatus product or process disclosed, or repre sents that its use would not infringe privately ow ned rights

This report has been partially funded by the U.S. Energy Research and Development Administration under Contract AT (04-3)-167, Project Agreement No. 17. The contents of this report are subject to change, and accordingly the recipient is requested not to reproduce or disseminate it further without prior written consent of General Atomic Company or the contracting agency.

Printed in the United States of America

Available from

National Technical Information Service

U.S. Department of Commerce

5285 Port Royal Road

Springfield, Virginia 22161

Price: Printed Copy $\$ 5.45$; Microfiche $\$ 2.25$ 


\section{DISCLAIMER}

This report was prepared as an account of work sponsored by an agency of the United States Government. Neither the United States Government nor any agency Thereof, nor any of their employees, makes any warranty, express or implied, or assumes any legal liability or responsibility for the accuracy, completeness, or usefulness of any information, apparatus, product, or process disclosed, or represents that its use would not infringe privately owned rights. Reference herein to any specific commercial product, process, or service by trade name, trademark, manufacturer, or otherwise does not necessarily constitute or imply its endorsement, recommendation, or favoring by the United States Government or any agency thereof. The views and opinions of authors expressed herein do not necessarily state or reflect those of the United States Government or any agency thereof. 


\section{DISCLAIMER}

Portions of this document may be illegible in electronic image products. Images are produced from the best available original document. 


\title{
(⿴囗十)
}

GA-A13386

UC-77

\section{PLANNING GUIDE FOR VALIDATION OF FISSION PRODUCT TRANSPORT CODES}

\author{
by \\ D. D. Jensen \\ M. J. Haire \\ J. E. Baldassare \\ D. L. Hanson
}

This report was prepared NOTICE

prepared as an account of work sponsored by the United States Government. Neither the United States nor the United States Energy Research and Development Administration, nor any of their employees, nor any of their contractors subcontractors, or their employees, makes any warranty, express or implied, or assumes any legal liability or responsibility for the accuracy, completeness or usefulness of any information, apparatus, product or process disclosed, or represents that its use would not infringe privately owned rights.

\author{
Work supported in part under \\ Contract AT(04-3)-167 \\ Project Agreement No. 17 \\ for the \\ San Francisco Operations Office
}

U.S. Energy Research and Development Administration 
i

i

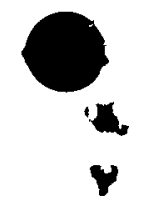




\section{FOREWORD}

The Planning Guide for Validation of Fission Product Transport codes was drafted to summarize the comprehensive effort planned for validation of the GA fission product transport codes RAD, FIPER, and PAD. This document provides a more detailed description of work proposed in the HTGR Chemistry National Program Plan. It covers work funded under various ERDA-supported and GAC supported programs.

This plan is restricted to analysis of currently funded in-pile tests, of operating HTGRs, and of the decommissioning of Peach Bottom. The question of the need for additional in-pile experiments for code validation is beyond the scope of this report. 


\section{ABSTRACT}

The program for validating fission product transport codes utilized in the design of the high-temperature gas-cooled reactor (HTGR) is described herein. The importance of fission product code verification is discussed as it relates to achieving a competitive reactor system that fully complies with federal regulations. A brief description of the RAD, PAD, and FIPER codes and their validation status is given. Individual validation tests are described in detail, including test conditions and measurements to be evaluated, and accompanying test schedules. Also included are validation schedules for each code inclusive through fiscal year 1978. Codes will be appropriately validated and utilized for fission product predictions for the Delmarva Final Safety Analysis Report (FSAR) due for release in early 1978. 
CONTENTS

FOREWORD. . . . . . . . . . . . . . . . . . . . . . i i i ABSTRACT. . . . . . . . . . . . . . . . . . . iv

1. SUMMARY . . . . . . . . . . . . . . . . . . . . . . 1-1

2. PURPOSE AND NEED. . . . . . . . . . . . . . . . . . . . . . 2-1

2.1 Cost Factors . . . . . . . . . . . . . . . 2-1

2.2 Federal Regulations. . . . . . . . . . . . . 2-1

3. DESCRIPTION OF FISSION PRODUCT DESIGN CODES . . . . . . . . . . 3- I

3.1 Gaseous Fission Product (RAD) Code . . . . . . . . . . 3-1

3.2 Metallic Fission Product (FIPER) Code. . . . . . . . 3-2

3.3 Plateout Distribution (PAD) Code........... . . 3-6

4. VALIDATION TESTS. ........................ 4-1

4.1 Introduction .................... 4-1

4.2 Reactors.................. . . 4-5

4.3 Loops. . . . . . . . . . . . . . . . 4-15

4.4 Capsules ..................... . . . . . . . . . . . . . .

4.5 Fuel Test Elements . . . . . . . . . . . . . 4-28

4.6 Contributions. . . . . . . . . . . . . . . . . 4-31

5. CODE VALIDATION SCHEDULE. . . . . . . . . . . . . . . 5-1

6. STATUS OF CODE VALIDATION ................. . . 6-1

6.1 RAD. ....................... 6-1

6.2 FIPER. . . . . . . . . . . . . . . . 6-2

6.3 PAD. . . . . . . . . . . . . . . . . . 6-9

7. VALIDATION PROGRAM SCHEDULE ............... . . 7-1

8. REFERENCES. . . . . . . . . . . . . . . . . 8-1 


\section{SUMMARY}

A testing program for verifying high-temperature gas-cooled reactor (HTGR) design methods related to fission product transport out of the fuel and around the primary coolant circuit is described. An objective of this program is the validation of $f$ ission product transport codes prior to the issuance of the Delmarva FSAR due for release in early 1978. Because of this objective, analyses of existing and near-term tests have been emphasized. However, an additional objective of the program is the broadening of capsule and surveillance element testing programs to include fission product measurements and analyses of value in later code verification and updating efforts. This program plan is meant to provide a well-defined, useful, and acceptable goal for fission product studies, including a systematic approach to analysis of fission product data which will become available.

Justification for this program is based upon the need to accurately know the disposition of fission products within the HTGR plant. Federal regulation 10 CFR 50 Appendix $B$ requires that adequacy of design be verified. Quality assurance requirement ANSI N45.2.11-1974 defines the extent of design verification as being dependent upon the relationship of the item under consideration to the health and safety of the public, the state of the art, and the similarity with previously proven designs. Since radionuclide migration characteristics are not well understood, a testing program must be undertaken to prove the adequacy of design methods. Design cannot be verified by alternate or simplified calculational methods where basic assumptions used to model transport have not been fully proven.

A second compelling reason for verifying fission product design calculations is that uncertainties in predictions of fission product release from the core could greatly affect fuel and plant capital costs if expensive multiple barriers to fission product release were required simply to compensate for those uncertainties. 
Three computer codes, RAD, FIPER (TRAFIC), and PAD, model radioactive nuclide transport in the primary coolant circuit and will be verified in large-scale tests.

1. RAD is used to estimate fission product inventories in the fuel elements, in the primary coolant, and on surfaces exposed to the primary coolant. Its predictions have never been verified in large-scale tests such as operating reactors. A great many small-scale tests (e.g., gaseous release from fuel rods, irradiation capsule measurements) have been conducted to determine release fractions from the fuel. However, these data are used as input to the code and do not confirm the code output or HTGR predicted inventories.

2. The FIPER (TRAFIC) code is used to calculate the release of metallic fission products from the HTGR core. Like the other codes, efforts to date have centered primarily in providing accurate assumptions for modeling and accurate input data through laboratory experiments. FIPER itself has not been completely verified in large-scale tests. Metallic fission product migration out of the fuel is among the less well understood fission product transport phenomena. Although most metallic species follow well-prescribed characteristics, certain very important metallic elements, such as cesium, are not represented by the fundamental assumption used in the FIPER code, Fickian migration. Laboratory measurements increasingly indicate the importance of alternate transport pathways of release. Thus, one objective of this testing program is to obtain both calibration factors and verification of fundamental assumptions for calculations involving these metallic elements from comparison of predicted and observed behavior. 
3. The PAD code calculates the distribution of radioactivity in the primary coolant circuit. More work has been expended verifying PAD than any other GA fission product transport code. PAD has been tested against plateout data obtained from the GA deposition loop, the Battelle Memorial Institute deposition loop, Dragon reactor heat exchanger measurements, and operational measurements from the Peach Bottom HTGR. This verification effort has been moderately successful but has not definitively verified the code. With the exception of Peach Bottom, none of the tests contained reference HTGR materials or operated at HTGR conditions. Peach Bottom data has heretofore been imprecise because of the inaccessibility to major primary circuit components of the operating reactor. Understanding of transport in the primary coolant circuit has lagged since studies on this began much later and were funded at much lower levels than studies of transport in the fuel element.

Table 1.1 lists the tests which will be used to validate fission product transport codes. The tests are divided into four general categories: reactors, loops, capsules, and test elements. There are a total of 15 separate verification tests. RAD will be validated primarily by analysis of the initial full-power operation of Fort St. Vrain. An additional wealth of information (verification of assumptions, input data, etc.) will be obtained from gaseous release measurements in capsules and test elements. FIPER will be verified primarily by evaluation of Peach Bottom decommissioning, Cadarache Pegase Loop (CPL), Saclay SPITFIRE Loop (SSL), and to a lesser extent by Fort St. Vrain operational studies. PAD code verification will depend primarily upon Peach Bottom decommissioning studies and to a lesser extent on CPL and SSL loop studies. The above listing is not exclusive. Nearly every test will contribute to validation of the codes.

In order for the goals of this program to be accomplished, 6-8 men per year (code development and validation personnel only) will be required 


\section{TABLE 1.1}

DESIGN METHOD VALIDATION

\section{Reactors}

Fort St. Vrain

Peach Bottom

AVR

Loops

CPL

SSL

SAPHIRE

Capsules

F-30, P13R, P13S

PI3Q, PI3T

\section{Test Elements}

FTE-7, 8, 9, 10, 14, 15, 17 FTE-16
Responsible Group

GA

GA-ORNL

HRB

GA-CEA

GA-CEA

HRB

GA

GA 
through fiscal year (FY) 1977, and two men from FY 1978-80. Some reordering of priorities will be required, as well as confiromation of funding sources and levels for the duration of program. 


\section{PURPOSE AND NEED}

This report describes the testing program for verifying HTGR design methods related to fission product transport out of the fuel and around the primary coolant circuit. The behavior of gaseous and metallic fission products in the HTGR is predicted through the use of the computer codes RAD, FIPER, and PAD which list circuit radioactivity inventories, model fission product migration, and describe the distribution of circuit activities. Code validation consists of comparison of experimentally observed releases and distribution with fission product behavior obtained from mathematical models using transport properties of individual components derived from small scale laboratory and irradiation tests. Validation of design methods relating to fission product transport is necessary to satisfy federal regulations by demonstrating long term fuel reliability, plant availability, and safety, and to ensure the most economical plant and fuel design commensurate with these requirements.

\subsection{COST FACTORS}

Some items associated with fuel and plant-side barriers which provide protection from fission products are listed in Table 2.1.

An accurate prediction of the behavior of fission products in the HTGR would permit the design of the simplest and most reliable barriers to fission product release. This would be a favorable development from the standpoints of cost and safety to the public.

\subsection{FEDERAL REGULATIONS}

In order to satisfy federal regulations defining quality assurance procedures relating to reactor design requirements, all design methods 
TABLE 2.1

ITEMS PROVIDING PROTECTION FROM FISSION PRODUCT RELEASE FUEL
a) Coated particles
b) Sorptive fuel rod matrix
c) Low coating failure during manufacture
d) Low coating contamination level during manufacture
e) Close control of coating and fuel rod properties

PLANT

To prevent release outside the plant:
a) Containment and containment liner
b) Low PCRV leak rate
c) PCRV relief value rupture discs

To handle released fission products:
a) Primary coolant clean-up systems
b) Primary coolant instrument line shields
c) Gaseous and liquid waste system
d) Reflector block shipping containers
e) Primary loop component removal casks

To provide safe plant operation:
a) Main steam and reheat steam redundant isolation valve leak tightness and closure time criteria
b) PCRV penetration flow restrictors and redundant shear anchors
c) Containment isolation valves 
must be validated. Specifically, validation of codes must be carried out in accordance with Code of Federal Regulations 10 CFR 50 Appendix B Quality Assurance Criteria for Nuclear Power Plants and Fuel Reprocessing Plants, and American National Standard Institute's Quality Assurance Requirements for the Design of Nuclear Power Plants, ANSI N45.2.11-1974. The former states, "Design control measures shall provide for verifying or checking the adequacy of design...by the use of alternate or simplified calculational methods, or by the performance of a suitable testing program." Verification of radionuclide design calculations by the use of alternate or simplified calculational methods is straightforward as long as a consistent set of basic equations, assumptions, and input data are used. There is, however, a more subtle aspect of design verification, that of verifying the applicability of the mathematical model. One can visualize fission product transport as migration of atoms across barriers. These barriers are resistances to the transport process and are connected in series and parallel arrangements yielding a total transport model - the design method. Such a network of transport paths is shown schematically in Figure 2.1 for metallic species migration out of the fuel element. As can be seen, transport models can become very complex.

Large scale experiments such as fuel irradiation capsules, fuel test elements, in-pile loops, and operating reactors which test the total transport model are required to validate design codes. These experiments are herein defined as integral tests because measurements derived from them are the result of the summed effects of multiple barriers to fission product release. This is in contrast to laboratory tests which generally supply information on a single barrier to fission product movement. Such tests are herein defined as differential tests because of the incremental nature of the measurement with regard to the total transport process. Incremental effects obtained from differential tests must be combined or integrated to yield the desired representation and ultimately the prediction of the amount of radionuclide release. Computer codes are used at GA to perform this function. The limited code validation efforts to date have been based upon summation of laboratory (differential) tests. 

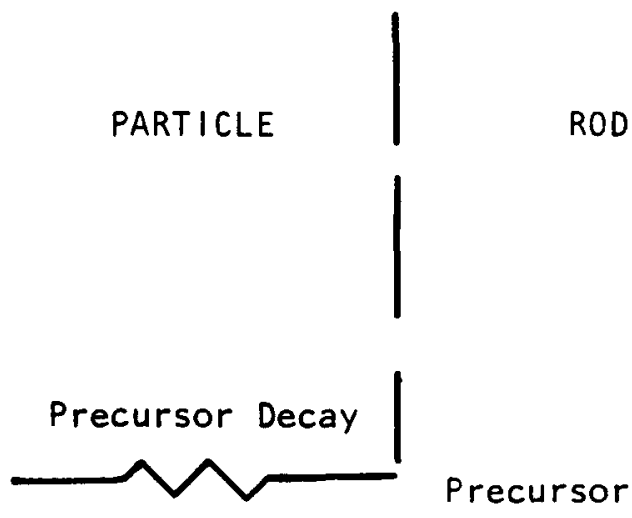

$\stackrel{n}{1}$

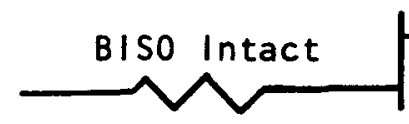

Precursor Decay

Thermal Diffusion

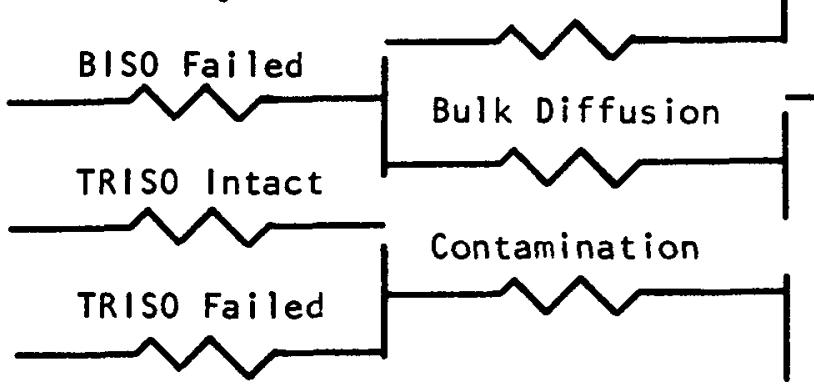

GAP -

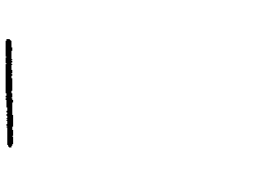

GRAPHITE WEB COOLANT
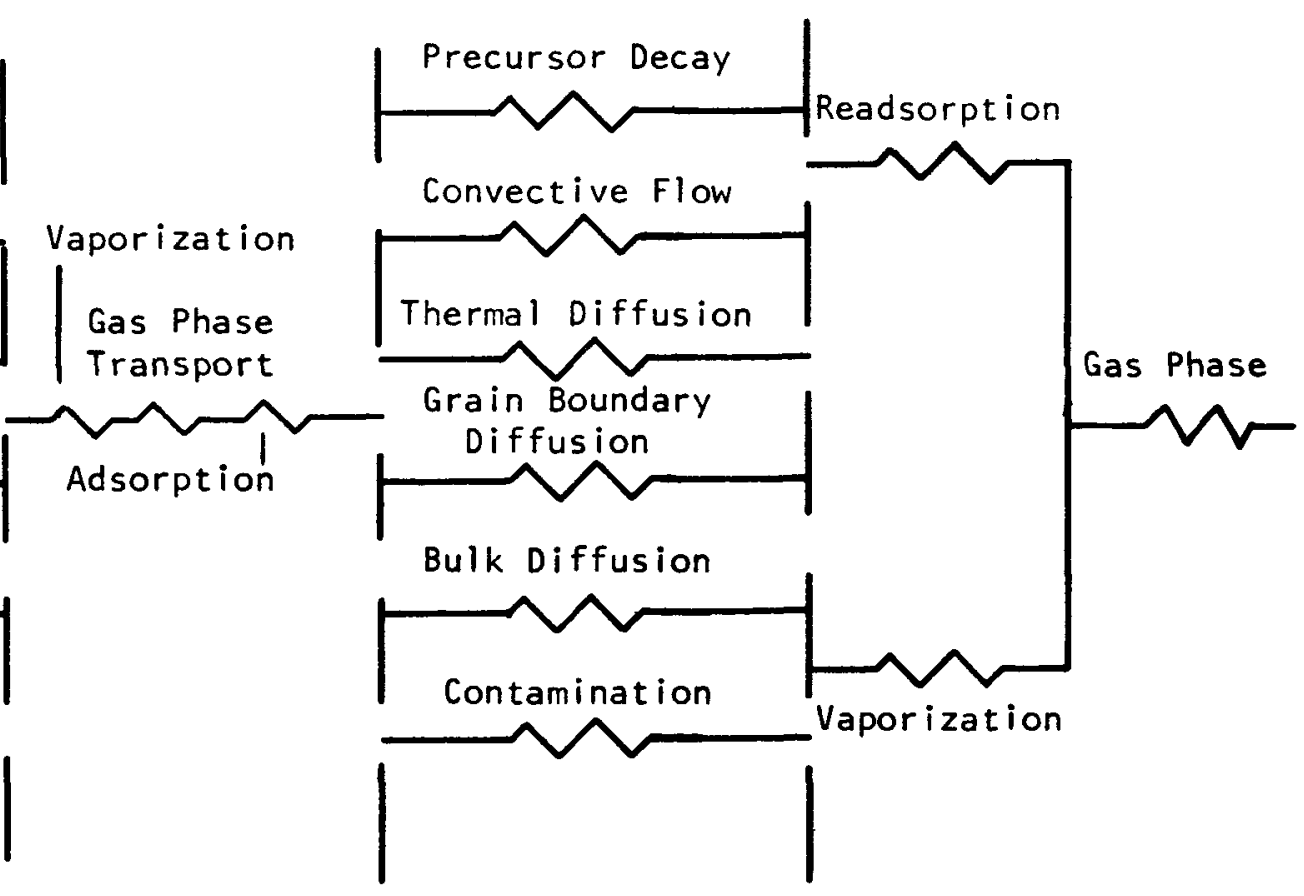

Fig. 2.1. System of resistances to metallic release. 
Historically at GA, each resistance (barrier) to release has been studied individually in the laboratory rather than as a system of resistances. Through understanding obtained from laboratory studies, individual models of separate resistances are formulated and data applicable to those individual models obtained. Laboratory measurements, therefore, are the bases of the network of resistances which form the design method.

Two concerns arise from relying upon differential data for design information. First, without having tested the total system, some pathway of fission product release into the helium coolant can be overlooked. Secondly, because of the necessity to be conservative, upper bounds to calculational input data and transport mechanisms are frequently chosen which result in grossly overpredicted radionuclide release from the core. Integral experiments provide both a calibration and a validation of the design methods. By comparing predicted to measured release quantities, pessimistic or optimistic factors can be factored into code predictions. In addition, integral tests allow the measurement of end quantities which result from the interaction of numerous pathways of release, thus reducing the possibility of neglecting a barrier to release of importance in actual reactor operation. Integral measurements will thus be designed to verify the validity of summing laboratory test data. Laboratory measurements are a prerequisite to understanding integral tests and will continue to be required in the testing of isolated assumptions or for the collection of basic input data for controlled experimental conditions. In addition, differential data will aid the evolution of transport models representative of HTGR fission product behavior.

ANSI N45.2.11-74 states, "the extent of the design verification required is a function of the importance to safety of the item under consideration, the complexity of the design, the degree of standardization, the state of the art, and the similarity with previously proven designs." The principal problem in formulating safe reactor design from a fission product standpoint is probably the radiation hazards resulting from fission product transport. The complexity of fission product transport phenomena requires confirmation 
of design methods based upon measurement of the system of barriers, since the understanding of transport phenomena is limited, as is the degree of standardization and similarity with previously proven designs. For these reasons large scale, integral tests are essential to satisfy fission product design method quality assurance requirements. 


\section{DESCRIPTION OF FISSION PRODUCT DESIGN CODES}

\subsection{GASEOUS FISSION PRODUCT (RAD) CODE}

The RAD code is used to estimate gaseous fission product inventories within the HTGR system. This code estimates the fission product nuclide inventories in the fuel elements, in the primary coolant, and on the surfaces exposed to the primary coolant. Activity levels are calculated for each isotope by assuming the source of each radionuclide in the fission process as well as well as decay of parent and grandparent fission fragments. $(1,2)$

The primary barrier preventing escape of radionuclides from the fuel particles into the coolant is the fuel particle coatings. Coatings are designed to contain volatile fission products and to capture fission products recoiled from the kernel. The fractional gaseous release of radionuclides from particles with intact coatings is predominantly due to heavy metal contamination in the coatings. The fractional release from particles with failed coatings is several orders of magnitude higher than that from fuel particles with intact coatings, but still significantly less than 1.0 .

The most important variable used by the RAD code is the steady-state fractional release of each isotope from the fuel element, $(R / B)_{i}$. The release to birth ratio is primarily dependent on the fission element, radioactive half-life, condition of the coating (intact or failed), and fuel element temperature. The fractional release is determined from in-pile experiments on as-manufactured fuel rods and fuel particles with failed coatings dispersed in fuel rods. From these measurements, diffusion parameters are calculated which are used as input to the RAD code.

The radionuclide activity in the coolant is directly dependent upon the release rate of each isotope from the fuel elements into the coolant, the removal rate due to the purification system, and the removal rate due to plateout on the surfaces of the primary coolant circuit. The removal constants due to the purification system and plateout are input data to the RAD code. When calculating circulating activity, the graphite fuel element web 
is conservatively assumed not to act as a barrier to release for gaseous radionuclides; i.e., the release from the fuel rod is equal to the release into into the coolant.

Table 3.1 presents a list of empirical and analytical assumptions made to estimate the gaseous fission product inventories within the HTGR.

One of the objectives of the code validation effort is the identification of needed code improvements. Work is presently underway to improve the RAD code in several areas where deficiencies are known to presently exist. Table 3.2 presents a list of potential improvements to be incorporated into the new code.

A preliminary version of an improved RAD is scheduled for use by April, 1975. The total RAD system (compatible with revised FIPER and PAD codes) is scheduled to be operational by Sept., 1975.

\subsection{METALLIC FISSION PRODUCT FIPER (TRAFIC) CODE}

The FIPER $Q$ and TRAFIC codes are used for calculating the release of metallic fission products into the primary coolant circuit of the HTGR system. These codes were developed at GA under the AEC Base Program. They provide numerical solutions of the diffusion problem described by equations of the form:

$$
\frac{\partial C_{i}}{\partial t}(\vec{r}, t)=s_{i}(\vec{r}, t)-\lambda_{i} c_{i}(\vec{r}, t)-\nabla \cdot \vec{j}_{i}(\vec{r}, t)
$$

where

$$
\begin{aligned}
c_{i}(\vec{r}, t) & =\text { volumetric concentration of the } i^{\text {th }} \text { diffusing specie } \\
S_{i}(\vec{r}, t) & =\text { volumetric source of the } i^{\text {th }} \text { diffusing specie } \\
\lambda_{i} & =\text { radioactive decay constant of the } i^{\text {th }} \text { specie }
\end{aligned}
$$


TABLE 3.1

LIST OF ASSUMPTIONS AND INPUT DATA UTILIZED IN THE PRESENT RAD CODE

Fuel Particles, Fuel Rod, and Graphite

\section{Assumptions}

1. Linear R/B vs square root of nuclide halflife

2. Stable and long-lived gaseous fission product inventory $100 \%$ released upon failure

3. Factor of 2 to 4 enhancement of $R / B$ for failed fuel due to carbide kernel hydrolysis.

4. No increase in $R / B$ due to burnup or fluence

5. Fractional release from carbide and oxide fuel is identical

6. Release from particle equals release from rod

7. Release from fuel rod equals release from fuel block

8. Release of chalcogens $=$ release of halogens $=$ release of noble gases

9. Approximate solutions of release from rate equations $\left(\lambda_{1}>\lambda_{2}>\lambda_{3}\right)$

10. Release is zero dimensional

11. Release occurs at steady state power level (single plant power, purification removal constant, plateout constant)

12. Contamination on coolant hole surface gives $R / B \leq 10^{-7}$

Experimental Input Data

1. R/B from failed fuel particles

2. $R / B$ from fuel rods (due to contamination in coatings, in matrix, from failed particles)

3. $R / B$ temperature dependence 
TABLE 3.2

POTENTIAL RAD CODE IMPROVEMENTS

1. Exact solutions to equations relating to decay of parent and grandparent radionuclides.

2. Variable plant operating power levels.

3. "Burst" effect (release of stored inventory at time of rupture.

4. Multiple sources.

5. Time dependent plateout removal constant.

6. Calculation of circulating tritium from He-3 source.

and

$$
\begin{aligned}
\vec{J}_{i}(\vec{r}, t) & =\text { diffusion current of the } i^{\text {th }} \text { specie } \\
& =-D_{i}(\vec{r}, t) \nabla C_{i}(\vec{r}, t) \text {, assuming Fickian diffusion applies. }
\end{aligned}
$$

These codes take into account the combined effects of (1) retention of fission product metals by fuel particles, (2) sorption of the metals by the fuel rod matrix material and graphite of the fuel elements, (3) evaporation of the metals from the graphite surface into the helium coolant through a boundary layer, (4) decay during diffusion transport, and (5) changes in fission rate (power), fuel temperature, and graphite temperature with time. $(3,4)$

The FIPER $Q$ code is a basic, rigorous code capable of solving the diffusion equation in one-dimensional slab, cylindrical, or spherical coordinates for a variety of boundary conditions. The diffusion equation is solved separately for each region of the transport problem, thus describing fission product transport from the fuel particle, through the fuel rod and structural graphite, to the coolant hole surface. 
The input data to the FIPER code needed to calculate release from fuel particles consist of particle boundary conditions, kernel and coating diffusion coefficients, diffusion activation energies, and fission fragment recoil range. The diffusion coefficients and activation energies are determined from laboratory experiments of fractional releases of individual isotopes from coated fuel particles. The experimental data indicate that the fractional release rate from BISO-coated particles in some cases is controlled by diffusion of fission products out of the kernel and in other cases by diffusion through the pyrocarbon coatings. The principal release from intact TRISO-coated particles is due to U-235 contamination in the outer pyrocarbon coating.

Input data to FIPER needed to calculate transport through the fuel rod and graphite web consists of diffusion coefficients for the rod matrix and graphite, diffusion activation energies and parameters used to calculate metallic vapor pressures. The fuel rod filler material is porous and hence the diffusion process through it is not assumed to limit metallic fission product release. A uniform concentration of metallic fission products through the fuel rod matrix is consequently assumed. From the resulting fuel rod surface concentration and input rod surface temperature, FIPER calculates the vapor pressure in the fuel rod-graphite gap. This vapor pressure determines a concentration at the fuel block-fuel hole surface and uses this surface concentration as a boundary value in solving the diffusion equations for the fission products in the graphite web. Fission product transport across the structural graphite web is then calculated by solving the diffusion equation using diffusion coefficient experimental data for metallic fission products in graphite.

The TRAFIC code is capable of rapid computation of block-average metallic fission product release at a great many spatial positions in the HTGR core. The need for such a code, as opposed to the more rigorous FIPER $Q$ solution, is due to the fact that release is a highly nonlinear function of temperature and temperature history. Temperatures vary in an irregular manner with space and time in the HTGR core, and a great many space points must be 
sampled in order to integrate the results and to locate critical areas for design purposes.

Table 3.3 presents a list of empirical and analytical assumptions made to estimate the metallic fission product inventories within the HTGR system. Validation test post-irradiation examination (PIE) measurements will be directed toward defining the validity of individual assumptions and input data.

Work should soon begin to improve the FIPER and TRAFIC codes in several areas. Table 3.4 gives a list of suggested advanced capabilities of the new FIPER. Improvements to the codes are scheduled to be completed by February 1976.

\subsection{PLATEOUT DISTRIBUTION (PAD) CODE}

Prediction of the plateout activity in the primary circuit of the HTGR is an integral part of reactor design. The quantity and distribution of fission products in the primary circuit influence not only shielding requirements and maintenance procedures but also safety analyses. The PAD code (Plateout Activity Distribution) was developed to assist in such predictions by supplying distributions of gaseous and condensed fission product species around the primary coolant circuit, particularly in regions outside the core. (5) PAD is a transient, one-dimensional mass transfer code; a finite difference solution is obtained for the coupled, non-linear differential equations describing the conservation of mass with a convective boundary condition. The coolant and surface concentrations are coupled by a concentration dependent sorption process (either Langmuir or Freundlich isotherms may be employed). The code allows for production by precursor decay and treats recirculation in a closed-loop. The PAD code has three options for treating deposition: 1) no sorption (e.g., a non-adsorbing noble gas); 2) no desorption (the surface is a perfect sink, or, more precisely, the vapor pressure over the surface is zero for all surface concentrations); and 3) desorption (an adsorption isotherm is employed such that at given surface temperature and partial pressure, an equilibrium surface concentration exists beyond which no further accumulation occurs). 
TABLE 3.3

LIST OF ASSUMPTIONS AND INPUT DATA UTILIZED IN THE PRESENT FIPER CODE

Release From Fuel Particles

Assumptions

1. Fickian diffusion applies

2. Thermal diffusion negligible

3. No diffusive release from intact TRISO

4. Single barrier to intact Blso diffusion release

5. Diffusion coefficients are independent of concentration

6. Total inventory released upon failure

7. Contamination treated as additive failure fraction

8. Release from single particles representative of release from large numbers of particles

9. Cumulative fission yields used

Experimental Input Data

1. Fuel particle boundary conditions

2. Kernel and coating diffusion coefficients

3. Activation energies

4. Fission fragment recoil range

Release From Fuel Rods

As sumptions

1. Diffusion rod matrix not controlling ( $D_{\text {rod }} \gg D_{\text {graphite }}$ )

2. Equilibrium between rod surface and vapor concentration

a. No kinetic limitation to transport across gap

b. Uniform partial pressure across gap

c. Mixed species effect represented by empirical formula

Experimental Input Data

1. Matrix diffusion coefficient

2. Activation energy

3. Vapor pressure 
TABLE 3.3 (continued)

LIST OF ASSUMPTIONS AND INPUT DATA UTILIZED IN THE PRESENT FIPER CODE

Release From Fuel Blocks

Assumptions

1. Fickian diffusion applies

2. Upper value of concentration dependent diffusion coefficient used

3. Equilibrium exists at graphite/helium coolant interface, i.e.,

a. No kinetic limitation in transport from graphite surface

b. Mixed species effect on vaporization represented by empirical formula

c. Sorption characteristics unchanged by neutron environment

4. Zero bulk coolant concentration (no readsorption in coolant channel)

Experimental Data Input

1. Graphite diffusion coefficients

2. Activation energies

3. Diffusivities

4. Vapor pressures

TABLE 3.4

SUGGESTED FIPER CODE IMPROVEMENTS

1. "Correct" release model from intact particles

2. Non-linear (concentration dependent) diffusion coefficients

3. Vapor pressures dependent upon nvt

4. Time dependent sorption ratio

5. Readsorption in coolant channel

6. Transport by convective flow

7. Transport by thermal diffusion

8. Multiregion problem (transport across gaps)

9. Consistent boundary conditions which couple particles, matrix, and graphite regions.

10. Diffusive transport across parallel paths (bulk and surface)

11. Account for precursor decay 
The rate equations utilized in the PAD code describe the mass balance for the coolant and surface fission product concentrations in sections of the reactor circuit with constant cross-sectional areas. The treatment is a simplified analysis giving surface concentrations and average coolant concentrations as a function of axial distance and time. It is assumed that the mass-transport process can be described to be between an average coolant concentration and a surface concentration separated by a thin gaseous boundary layer film. The coolant and surface concentrations of each fission product are dependent on a source term, such as the release of the fission product from the reactor core, on the decay of the fission product itself, on mass transfer between the coolant and surface, and on axial convection around the reactor circuit.

Table 3.5 summarizes the assumptions utilized for each circuit component modeled by the PAD code.

Table 3.6 lists potential improvements to be incorporated in the PAD code during code revision effort. 
TABLE 3.5

LIST OF ASSUMPTIONS AND INPUT DATA UTILIZED IN THE PRESENT PAD CODE

\section{Assumptions}

1. Conservation of mass exists between convective coolant and boundary surfaces within closed loop.

2. Coolant and surface sources of $k$ species $(k \leq 5)$ are spatially dependent, time independent.

3. Complex circuit geometries modeled by banks of parallel cylindrical tubes of equivalent diameter to give proper surface area, velocity, and transit time.

4. Mass transport from coolant to surface described by film coefficient determined from empirical correlation.

5. Coupled 5 member decay chains are utilized with appropriate branching ratios.

6. Surface sorptivities are either infinite or as described by Langmuir or Freundlich adsorption isotherms.

7. Gaseous diffusivities can be obtained by extrapolating experimental Cs in He data.

8. All plateout nuclides are transmitted as molecular species; no circulating particular matter (dust) considered.

9. Deposition is a surface phenomena (no penetration into bulk).

10. Core release of gases (including 1) is uniform.

Input

1. Sorption isotherms of $1, \mathrm{Cs}$, and $\mathrm{Sr}$ on graphite.

2. Time-average source terms.

3. Gaseous diffusivities. 
TABLE 3.6

POTENTIAL PAD CODE IMPROVEMENTS

1. Revised numerical solution techniques.

2. Empirical time-dependent source terms.

3. Section-by-section specification of mass transfer correlation.

4. More generalized surface temperature distributions.

5. Provision for penetration of surface deposits into bulk of structural material.

6. Inclusion of effects of circulating particulate matter on plateout distribution. 


\section{VALIDATION TESTS}

\subsection{INTRODUCTION}

\subsubsection{Summary of Tests}

Large scale integral validation tests can be divided into four general categories: 1) reactors, 2) loops, 3) capsules, and 4) test elements. (In some instances test element and capsule tests are not truly integral tests because they may not include fission product transport through all release barriers, i.e., transport in helium coolant and deposition on surfaces.) Table 4.1 lists individual validation tests to be studied in each general category and the responsible organization for performing the validation. Arrangements are being made for organizations other than GA to perform part of the validation work. It is presently planned that GA will rely solely upon the work reported by these organizations, and not repeat the analyses. However, common assumptions, input data, and design methods will be used by all groups. The results of the analyses will be available to all participants.

Sections $4.2-4.5$ discuss the specifics of each test and the analyses schedules.

\subsubsection{Interfaces}

Three separate groups at GA form the design validation effort: 1) the laboratory group, primarily the Fuel Chemistry Branch, which provides basic data for design calculations, 2) the methods group, the Fuel Methods Department, which insures that adequate calculational capability is available, and 3) the validation group, primarily the Core Performance Branch, which combines data and calculational methods and uses them to analyze fission product transport. It is the latter group which predicts fission product behavior and compares the results to measured experimental values.

Figure 4.1 shows a schematic of how these three groups typically interface. The first step in the validation program is the planning of the 
TABLE 4.1

\section{DESIGN METHOD VALIDATION}

Reactors

Fort St. Vrain

Peach Bottom

AVR

Loops

CPL

SSL

SAPHIRE

Capsules

F-30, P13R, P13S

PI3Q, PI3T

Test Elements

FTE-7, 8, 9, 10, 14, 15, 17

FTE- 16
Responsible Group

GA

GA-ORNL

HRB

GA-CEA

GA-CEA

HRB

GA

GA 


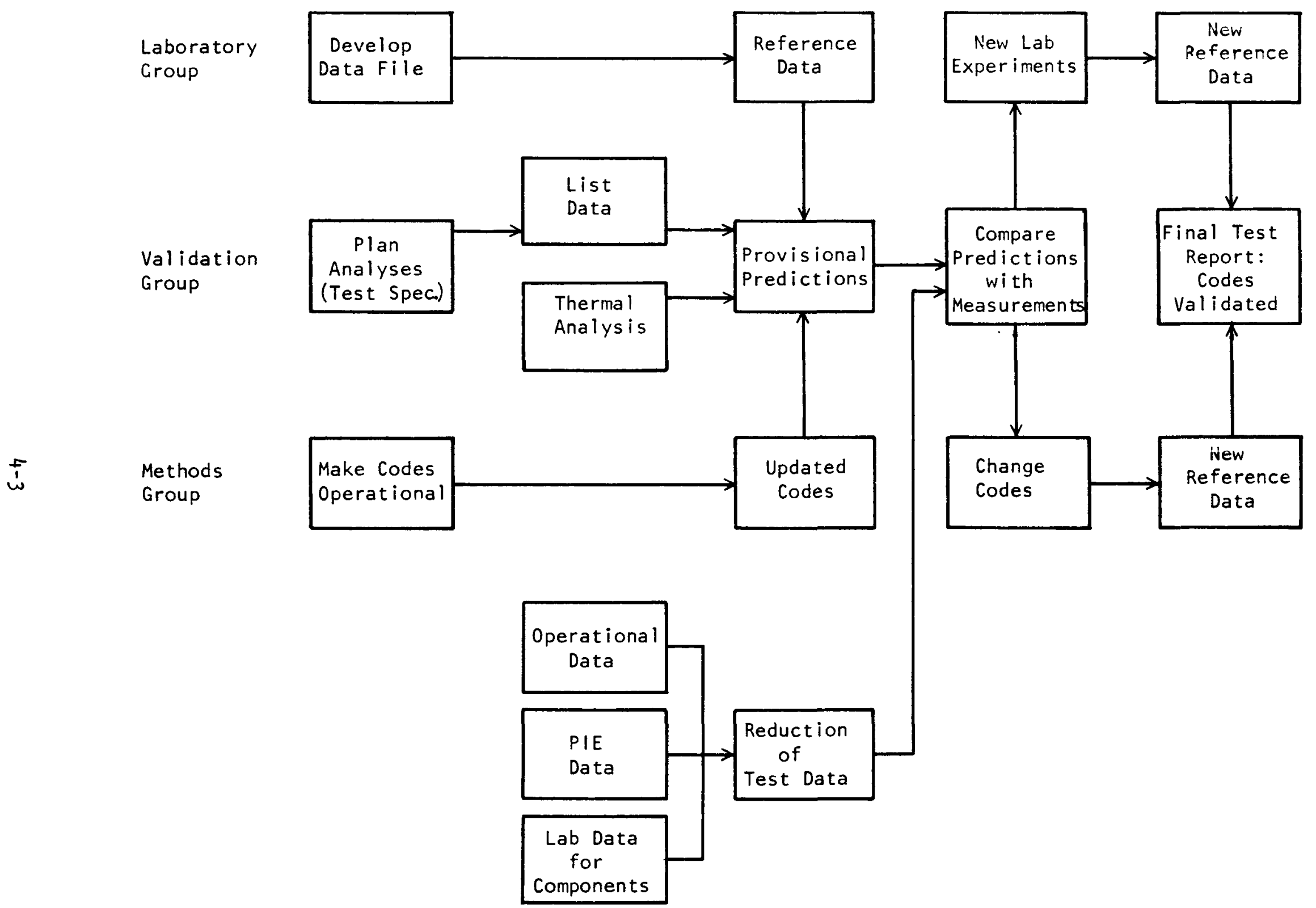

Fig. 4.1. Flow chart for integral validation tests. 
validation effort. This document is a report of that plan. Once the various tests to be used to validate the design methods have been selected, the operational test data must be systematically reduced to a form usable in the analyses. The operational thermal analysis is listed separately (Fig. 4.1) since operational temperatures are such an important part of any fission product transport analysis. Using Fuel Design Division reference data and codes, provisional predictions of fission product behavior are made by the validation group. When these predictions are completed, they are compared to test data. These analyses may suggest refinements in the data file or perhaps indicate directions for improvement in predictive methods. Thus, new laboratory experiments may have to be performed to explain anomalies under isolated, controlled conditions. The calculational methods may require modification to reflect the new understanding derived from the test data. Using new reference data and new updated reference computer codes, predicted fission product behavior will again be compared to experimental measurements. This interaction between the three concerned groups continues until reasonable confidence has been developed that the behavior in an HTGR can be predicted and an adequate design method has been evolved. This sequence of steps shown is repeated for each test used to evolve the design methods, and the sum of the findings utilized to validate all codes.

\subsubsection{Role of Uncertainty Analyses}

Evaluation of uncertainties in the input data and the assumptions which form the transport model play a major role in code validation analyses. These uncertainties must be quantified to yield a predicted release within acceptable confidence limits. Without uncertainty analyses, the large number of parameters utilized as input to the codes could be adjusted to yeild predictions in agreement with observed measurements for selected tests while masking errors in code input and assumptions. Further predictions with the selected parameters would likely show marked deviation from other test measurements, and would make predictions of HTGR fission product behavior of lesser validity. 
Analyses of uncertainties are being performed in a separate program, Safety Program 189a No. 13822, the Accident Initiation and Progression Analysis (AIPA) program. One objective of this effort is to define the uncertainties associated with the radiation dose upon initiation of an accident event. Uncertainties in the input data are established and used as input to existing design methods to determine the variation in predicted releases. This is a perfectly valid procedure if there is absolute confidence in the accuracy with which the design methods represent transport phenomena. The validation program takes the objectives of this work a step further and will correlate the analytical uncertainty with experimental data.

\subsection{REACTORS}

Reactors offer the greatest opportunity for validation of the RAD, PAD, and FIPER fission product transport codes since measured fission product releases result from the effects of all summed barriers to release. As such, four high-temperature, gas-cooled reactors will be studied in the validation effort: (1) Fort St. Vrain, (2) Peach Bottom, (3) Dragon, and (4) AVR.

\subsubsection{Fort St. Vrain HTGR}

An integral part of the planned FSV surveillance program will be the collection of data to aid validation of transport codes used for predictions of fission product behavior in the large HTGR.

Purpose. The purpose of FSV data analysis will be the verification of all fission product transport codes. Initial full power plant operation offers the single best opportunity to verify the gaseous fission product release code (RAD) of all validation tests. In addition, operational data from the fast gas and grab samplers will allow verification of an important RAD code assumption: the square root of half-life dependence of fission gas release from outer pyrocarbon particle coatings. PAD code verification will be aided by measurements derived from the iodine monitor and plateout probes. Data from the surveillance elements should aid FIPER code verification. 
Test Description and Operating Conditions. Fort St. Vrain is an $841 \mathrm{MW}(\mathrm{t})$ reactor with a core design and steam generator arrangement similar to that of the large HTGR. (6) (See Fig. 4.2) The core is made up of 1482 hexagonal graphite fuel elements, $78.7 \mathrm{~cm} \mathrm{high} \mathrm{and} 35.6 \mathrm{~cm}$ across the flats arranged in a hexagonal array. Each (standard) fuel element contains $108,1.59 \mathrm{~cm}$ dia. coolant holes and $210,1.27 \mathrm{~cm}$ dia. fuel holes containing bonded rods of coated fuel particles (see Fig. 4.3). The $(U, T h) C_{2}$ fuel kernels are coated with four separate layers of isotropic pyrocarbon and silicon carbide to provide barriers to gaseous and metallic fission product release. The particles are formed into $5.08 \mathrm{~cm}$ long, $1.25 \mathrm{~cm}$ dia. rods using a carbonaceous binder, and fired at high temperature to form the fuel rod.

Helium coolant gas at $406^{\circ} \mathrm{C}$ passes downward through the coolant holes within the fuel elements into the plenum area under the core. The $785^{\circ} \mathrm{C}$ gas then passes upward through the steam generator where it gives up its heat to water and steam. The coolant then passes to the suction side of the helium circulators, and is routed to the top of the core to complete the coolant passage about the primary circuit.

Test Measurements. Commercial operation of FSV is expected in Summer, 1975. RAD code verification data will include $R / B$ measurements during initial riseto-power and full-power operation. This data should be very useful since all types of fuel in FSV have been well characterized by extensive preirradiation fission gas release studies on fabricated fuel rods. Since the uncertainty associated with the failed fuel particle distribution will be low during initial operation, gaseous releases can be confidently predicted with calculated temperature and power distributions. This data will be collected with the fast gas and grab samplers to determine short-lived and long-lived fission gases, respectively. Data from the plateout probes will yield plateout per pass constants for condensible species during passage by the steam generators, as well as circulating fission metal concentrations in the coolant at the probe locations. Measurements of circulating iodine activity will yield an iodine plateout per pass constant and measurements of $\mathrm{Xe}-133$ and $\mathrm{Xe}-135$ activity during shutdown will permit 


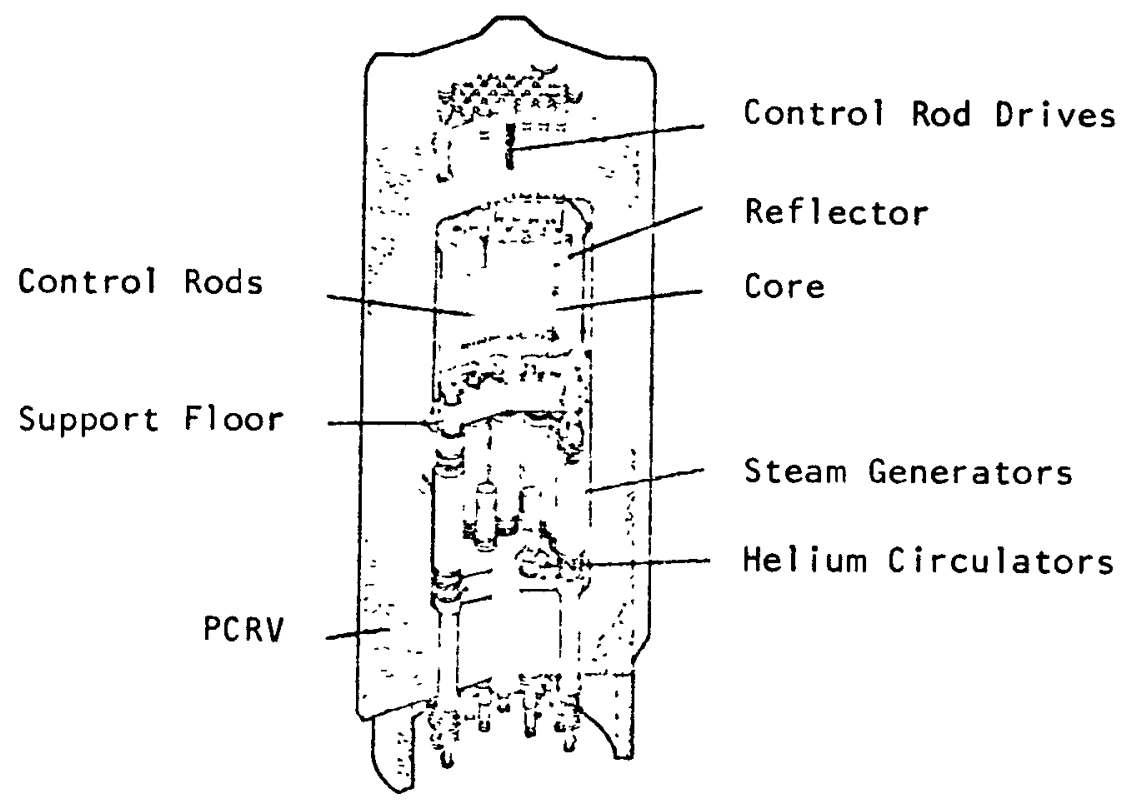

Fig. 4.2. Fort St. Vrain reactor arrangement in PCRV.
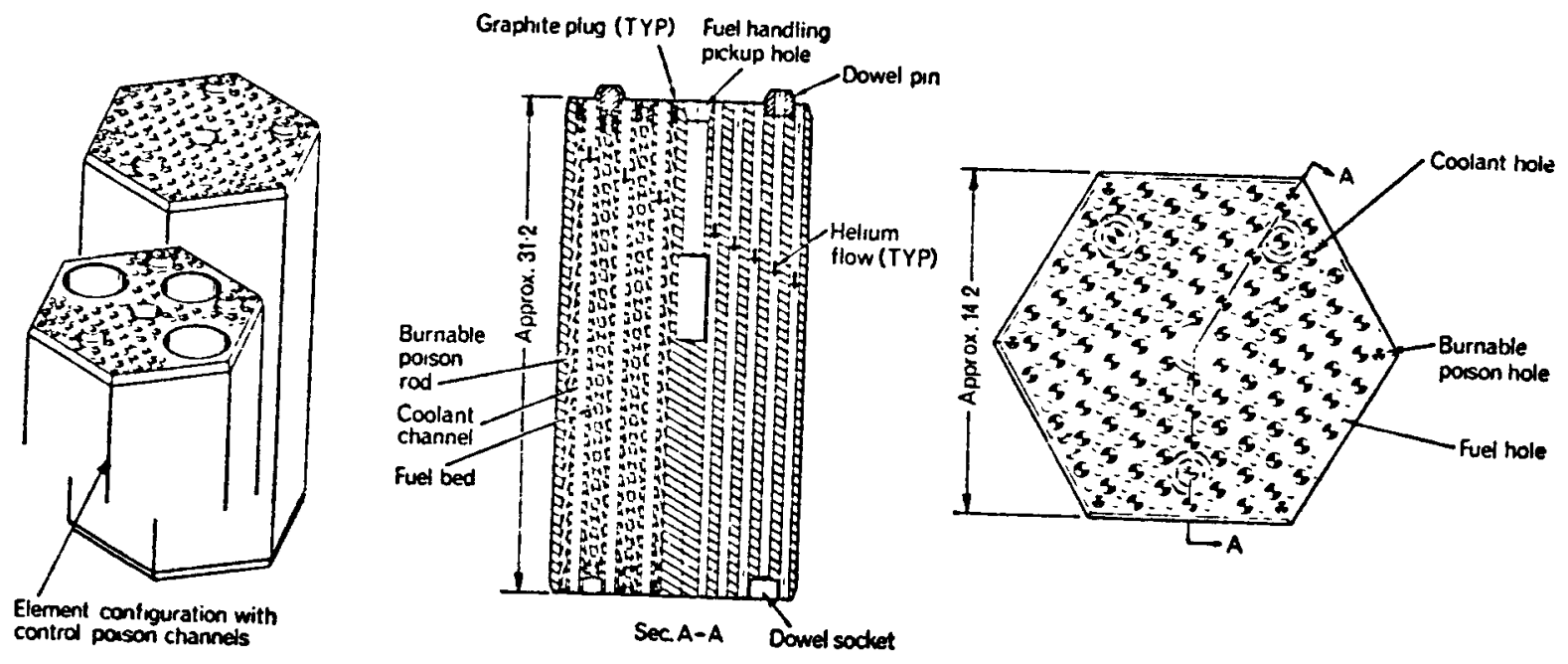

Fig. 4.3. Fort St. Vrain fuel element. 
calculation of the total iodine release (thus serving as verification of the assumption that halogens behave as rare gases in fuel particles).

A fuel surveillance program has been developed for FSV with the cooperation of the Public Service Company of Colorado. A total of 32 surveillance fuel elements having detailed preirradiation metrology data will be irradiated in FSV. Plans are to remove several fuel elements during each core reloading. Measurements of metallic profiles in graphite webs, coupled with determinations of total metallic release (flux) obtained during PIE gamma scanning of fuel particles may yield data of value in FIPER validation (if release is sufficient to allow accurate measurements). Assumptions of the particle failure model utilized in RAD will also be verified by measurements of $R / B$ for fuel rods during PIE.

\subsubsection{Peach Bottom HTGR}

The Peach Bottom decommissioning effort affords a unique opportunity to advance HTGR fuel and plant technology. Consequently, an ambitious end-of-life research program has been developed and endorsed by the AEC and EPRI for joint sponsorship. This new program will generate substantial quantities of fission product transport data and will be a principal part of the fission product transport code validation program.

Purpose. The purpose of this program is to validate the RAD, PAD, and FIPER codes utilizing operational and end-of-life (EOL) data from a power generating HTGR reactor that has operated for an extended period of time. Specific objectives of the validation program include (1) validation of PAD using plateout data obtained from EOL studies of primary coolant circuit components, (2) validation of FIPER using data obtained from ORNL PIE analysis of five driver elements, and (3) validation of RAD using beginningof-life (BOL) data from purged fuel test elements. 
Test Description and Operating Conditions. The $40 \mathrm{MW}(\mathrm{e})$ Peach Bottom was the first nuclear power generating station to produce commercial electric power at modern steam conditions of $99 \mathrm{~atm}$ and $538^{\circ} \mathrm{C}$. This AEC demonstration plant began commercial operation in June, 1967. After concluding that operation of a third core would be uneconomical because of the plant's small size, Philadelphia Electric Company and GA decided to shut down and decommission the plant; final shutdown occurred on October 31, 1974 after 1349 EFPD and 1,200,000 MW-hr of electrical energy generation. A complete description of the Peach Bottom HTGR can be found in the Peach Bottom Final Hazards Summary Report (FHSR) ${ }^{(7)}$ and in Ref. 8.

The primary circuit is shown in Fig. 4.4. The core of the Peach Bottom HTGR is composed of 804 individual fuel elements vertically oriented in a close-packed array. The core array is cylindrical, with an effective diameter of $2.74 \mathrm{~m}$ and an active height of $2.29 \mathrm{~m}$. Cold helium at $23.8 \mathrm{~atm}$ and $326^{\circ} \mathrm{C}$ enters the upflow core where it is heated to $704^{\circ} \mathrm{C}$ during passage through the tricusp-shaped channels formed by the elements. From the core exit plenum, the flow is split between two parallel loops. The hot helium is directed toward the vertical $U$-tube steam generators $v i a$ the inner pipe of a concentric duct. After passing over the tube bundles and recombining in the annular passage between the tube bundle shroud and steam generator shell, the cool helium is returned to the reactor pressure vessel by the helium circulator. After cooling the core barrel, the helium reenters the core to complete the loop.

The Peach Bottom fuel element, shown in Fig. 4.5, has an overall length of $3.66 \mathrm{~m}$ and an outside diameter of $8.89 \mathrm{~cm}$ and consists of an upper reflector section, a fuel-bearing middle section, a bottom reflector section, and an internal fission product trap containing activated carbon. A low-permeability sleeve extending from the upper reflector to the bottom reflector contains the fuel compacts and the internal fission product trap. The fuel compacts consist of BISO coated uranium-thorium carbide fuel particles in a graphite matrix. 


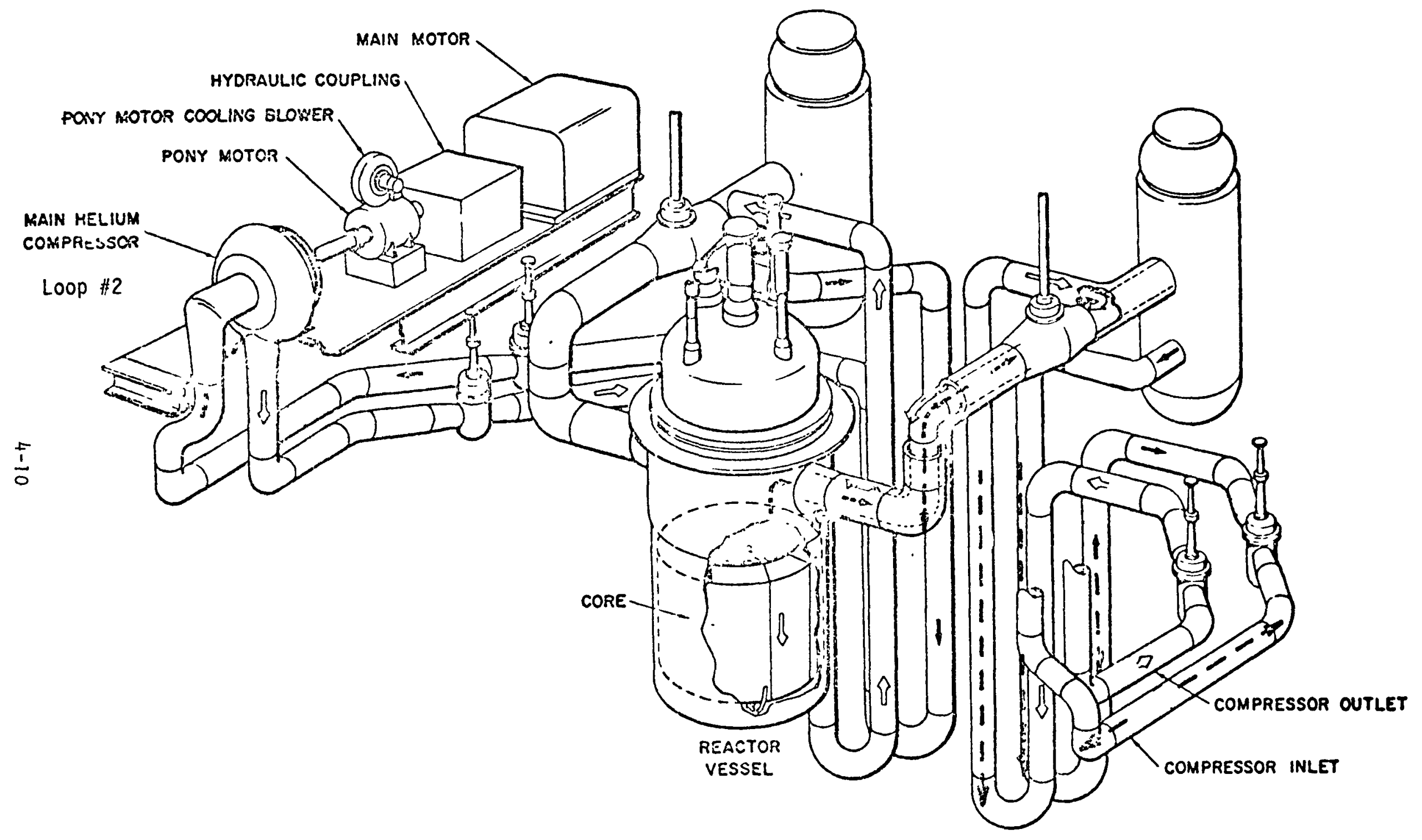

Fig. 4.4. Isometric Drawing of Peach Bottom HTGR Primary Coolant System 


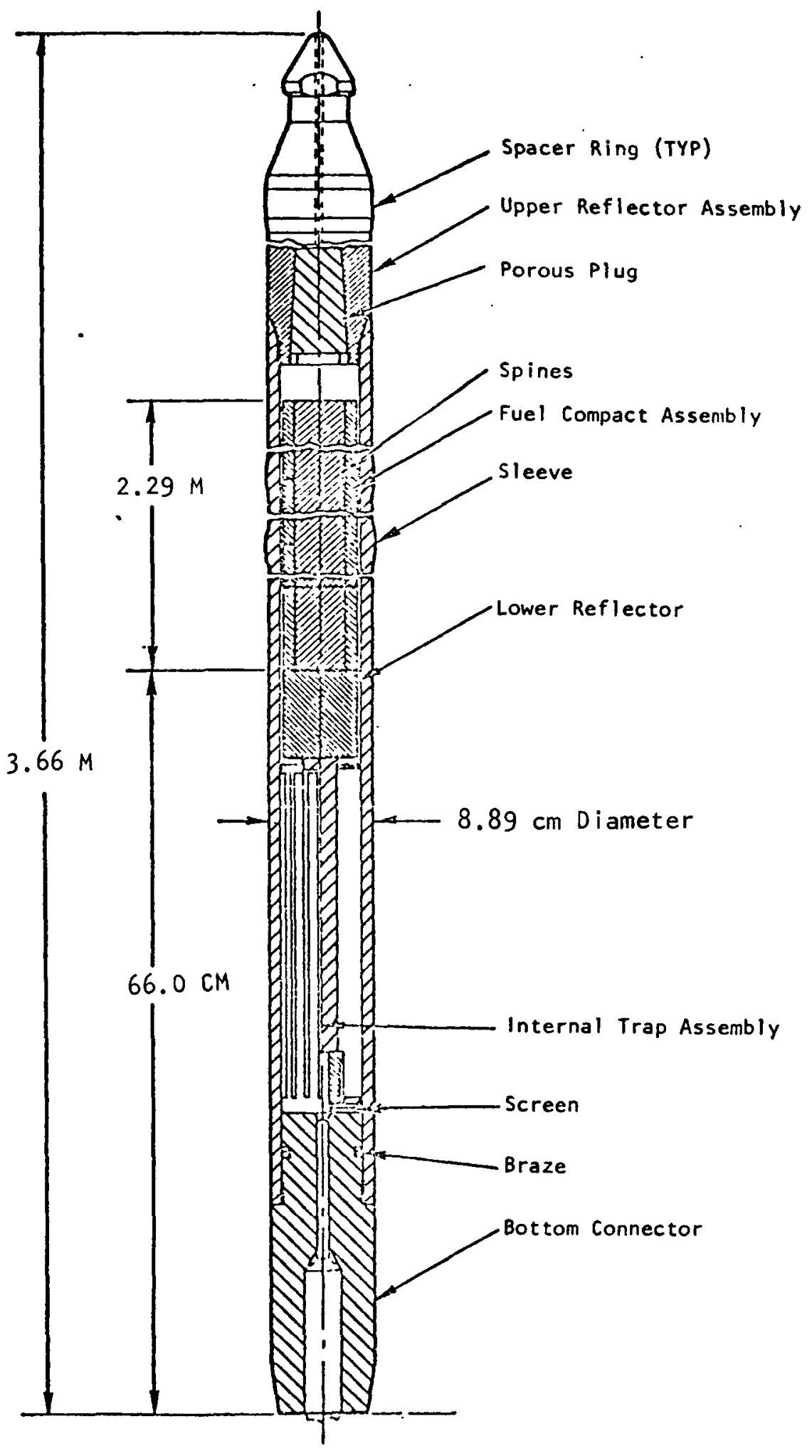

Fig. 4.5. Peach Bottom Fuel Element

$$
\text { 4-11 }
$$


Helium purge gas enters each fuel element through a porous plug in the upper reflector piece and then flows downward and around the fuel compacts, sweeping volatile fission products out of the gap between the fuel compacts and the graphite sleeve. The purge gas then flows through the internal trap, where some of the fission products are absorbed by the activated carbon. Volatile fission products leaving each internal trap enter a purge line leading to the external helium purification system.

Test Measurements. Considerable fission product transport data have already been obtained by making operational measurements throughout reactor operation. These measurements, which have been carried out by GA and ORNL with the cooperation of Philadelphia Electric Co., include: (1) fission gas release, (2) diffusion probe analyses, (3) tritium surveys, and (4) external gamma surveys of accessible ducts. In addition, several Core 1 and Core 2 driver fuel elements have been examined at GA and ORNL. These investigations have already yielded valuable fuel performance and fission product transport data $(9,10,11)$ and should provide even more valuable insight when coupled with the results of the anticipated EOL program.

The scope of the Peach Bottom EOL RED Program as proposed to ERDA and Electric Power Research Institute (EPRI) for sponsorship is shown in Table 4.2. In terms of transport data for code validation, the most important features of the program are: (1) detailed PIE of five driver elements at ORNL, and (2) determination of plateout distribution (hence total core release) by in situ gamma scanning and radiochemistry of specimens removed from steam generator and ducts. The axial and radial power distributions that prevailed in Core 2 should be accurately known subsequent to analysis of the fuel gamma scans and PIEs. The improved power distributions coupled with metrology data from PIEs, in combination with better nuclear and thermal methods, should provide much more reliable time-temperature-power histories. Computer calculations can then be performed using current particle performance models $(12)$ to predict the amount and distribution of particle failure for comparison with PIE-determined failure fractions and to provide input for fission gas and metallic release calculations. In turn, release predictions can be compared with core-average gas release and individual purged element 
TABLE 4.2

Portion of Peach Bottom EOL RED Program Utilized to Validate Fission Product Transport Codes

A. ERDA Funded work at ORNL

1. External gamma scan of Loop No. I ducts

2. PIE of 5 driver fuel elements

B. Proposed for Joint EPRI/ERDA Sponsored RED Program*

1. External gamma scan of Loop No. 2 ducts

2. Gamma scan of steam generator from water side

3. Fuel element gamma scans

4. Trepan Loop No. 1 ducts at approximately 10 locations

5. Remove sections of steam generator tubing

6. Internal gamma scan of Loop No. 1 ducts

*subject to ERDA and EPRI approval.

measurements and with circuit inventories (from integrated plateout distributions). Finally, PAD code calculations will be made in order to compare predicted and measured deposition profiles.

\subsubsection{AVR HTGR}

Purpose. GA will closely review operational data and analyses supplied by Hochtemperatur-Reaktorbau (HRB) for the German (AVR) pebble bed reactor as an aid to validation of fission product transport codes. No direct analysis is planned by GA.

Test Description and Operating Conditions. The $15 \mathrm{MW}(\mathrm{e})$ AVR nuclear power station is a pebble bed reactor which first went critical in 1966. (13) The cylindrical reactor core contains approximately 100,000, $6 \mathrm{~cm}$ diameter fuel spheres which are randomly packed. During operation they are continuously 
withdrawn from the bottom of the reactor core and returned to the top of the pebble bed, so that a continuous circulation of pebbles takes place. Spent elements are removed from the cycle during this process and replaced by new pebbles. There is no excess reactivity in this system and only safety rods are provided for startup and shutdown purposes. The fuel consists of graphite-matrix spheres containing a dispersion of pyrolytic carbon coated $(T h, U) C_{2}$ particles. Some elements made with oxide fuel particles have been used since 1972. Helium coolant circulates in an upward flow through the bottom reflector, the pebble bed, and the top reflector to the steam generator. The operating experimental conditions are typically: thermal power, $46 \mathrm{MW}$; mean hot gas temperature, $850^{\circ} \mathrm{C}$; helium flow through loop, $15 \mathrm{~m}^{3} / \mathrm{hr}$; inlet gas temperature, $300^{\circ} \mathrm{C}$.

Test Measurements. Gaseous fission product concentrations in the coolant are routinely determined. In addition, two tests have been set up to determine the concentration of solid fission and activation products in the AVR coolant. Dust measurements are made with the use of a high flow dust filter installed to quantitatively trap dust in a cold coolant gas line. Together with the dust examinations it is possible to measure the radioactive nuclides, which are adsorbed on the dust particles, and thus deduce the concentration of fission products in the cold part of the primary circuit. Plateout behavior is also studied by the use of a hot gas sampler (VAMPYR loop) containing absolute filters for dust collection and a water cooled plateout tube for measurement of condensible radionuclides.

Like the Dragon data, the AVR fission product data will not be analyzed in this present code validation program. However, investigators at HRB have already begun to use VAMPYR data to test the validity of the PAD code as well as their own plateout code. They are particularly interested in the extent to which deposited activity may penetrate into the bulk of structural materials. As with the Dragon analysis, the progress of the HRB analysis will be closely monitored by the validation group. 


\subsection{LOOPS}

Several loop experiments containing HTGR fuel elements and reactor components have been and are being irradiated in French reactors. The objective of these experiments is to study fission product transport and evaluate fuel performance emphasizing French materials. The intent is to provide adequate data to license an HTGR of GA design in France.

\subsubsection{Cadarache Pegase Loop (CPL)}

Purpose. The CPL experiments in the Pegase reactor are designed to measure integral fission product transport properties under well instrumented and controlled conditions. As such, one purpose of the experiments is the validation of the transport codes RAD, PAD, and FIPER which predict fission product release from HTGR fuel elements and the plateout distribution in the HTGR primary coolant circuit. (14) Validation is achieved by comparing the predicted and measured values of fission product release and plateout concentrations in the CPL loop experiments. These experiments also study the basic fission product transport processes through graphite and the coolant circuit at design and upset coolant impurity conditions.

Test Configuration. Each CPL loop consists of: (1) a test assembly containing a fuel element, a reflector block, and a test shell and tubular heat exchanger; (2) a loop heat exchanger to regulate the fuel element inlet temperature; (3) a blower to circulate coolant; (4) a purification system to regulate coolant impurity levels; and (5) an injection system to maintain desired concentrations of hydrogen and water impurities in the coolant. The fuel element and reflector block used in CPL have the same coolant and fuel hole diameters in the same configuration as the HTGR. The fuel rods and fuel particles are similar to those planned for use in the HTGR. Bare fuel kernels are included in the fuel element, and serve as the predominant source of fission product release in the experiment. These bare kernels will release sufficient metallic fission products from the fuel element such that the resulting heat exchanger surface activity will correspond to expected HTGR primary circuit metal surface activity after years of reactor operation. 
The test shell and tube heat exchanger contains 187 flow tubes made from five different alloys. Of these, 170 tubes are made of Incoloy 800 . The heat exchanger measurements determine the plateout distribution of condensible fission products on the different metal surfaces at approximate temperatures present in the large HTGR. The limiting test conditions to simulate HTGR operation are presented in Table 4.3.

Test Measurements. Preirradiation test measurements consist of a detailed examination of the test heat exchanger surfaces including the chemical composition of the surface and the thickness and condition of the oxide layer. The weight and dimensions of the fuel and reflector blocks are measured along with the basic chemistry experiments designed to characterize material properties of the nuclear graphite. Operational test measurements include temperature readings at 11 points in the loop at least twice a day and continuous monitoring of the flow rate, total circulating radioactivity, and coolant impurities.

The postirradiation examination consists of a study of the mass balance, i.e., fission product release and profile measurements made on the fuel elements, the reflector block and the heat exchanger. Dust is expected to be formed in the test heat exchanger during some of the tests. This will allow study of the transport of fission products which adhere to dust. In addition, blowdown experiments are conducted out of pile on selected tube specimens taken from the heat exchanger to study the reentrainment characteristics of plateout material under accident conditions. Table 4.4 summarizes the planned CPL-2 series of tests. This test program is presently a private program of CEA and GA.

\subsubsection{Saclay SPITFIRE Loop (SSL)}

Purpose. In the SSL experiments, large HTGR fuel is irradiated in the OSIRIS reactor to high fast fluence and high fuel burnup. (15) The purpose of the experiments is to determine the fuel particle failure fraction, fission gas release, and the physical changes occurring in an integral assembly of fuel rods and graphite due to irradiation. Using this experimental data, 
TABLE 4.3

Limiting Test Conditions for CPL Loops

\section{Parameter}

1. Cesium release from fuel element

2. Temperatures:

a. Heat Exchanger Tube Wall Maximum Minimum

b. Coolant Temperatures at the entrance of the exchanger

3. Total Oxidant Impurity Level

4. Coolant pressure
Limiting Value

$\geq 50 \mathrm{mC}$ i

$>600^{\circ} \mathrm{C}$

$<400^{\circ} \mathrm{C}$

$740^{\circ} \mathrm{C}<\mathrm{T}<840^{\circ} \mathrm{C} \pm 20^{\circ} \mathrm{C}$

$10 \mathrm{ppmv} \pm 3 \mathrm{ppmv}$ (CPL 2/1)

1 ppmv - 100 ppmv (CPL 2/3)

50 atm $<p<60$ atm \pm 2 atm

TABLE 4.4

Summary of CPL Operating Characteristics

Test Operating Characteristics

CPL 2/1 Limiting HTGR operating conditions

CLP $2 / 3$ Identical to CPL $2 / 1$ but with high coolant water impurity levels

CPL $2 / 4$ Identical to CPL $2 / 1$ but simulating design basis depressurization accident 
the fission product codes RAD, PAD, and FIPER will be verified by comparing the predicted and measured values of fission product release.

Test Configuration. The experimental fuel element is designed to represent a geometric unit cell of an HTGR fuel element. The fuel element, $49.5 \mathrm{~cm}$ long, is made of either Pechiney $P_{3}$ JHAN graphite $(S S L-1)$ or $H-451$ (SSL-2) with 3 fuel holes and 4 coolant channels. Each fuel hole contains 9 fuel rods. A graphite plateout sleeve is installed in the loop downstream from the outlet of the coolant channels to absorb metallic fission products released from the fuel during irradiation. This sleeve consists of two $40 \mathrm{~cm}$ long concentric graphite rings with a radial gap of $0.4 \mathrm{~cm}$ between them for coolant passage. Table 4.5 presents the SSL operating conditions utilized to simulate HTGR operation.

Test Measurements. The preirradiation measurements for this experiment consist of a dimensional analysis of the fuel element and detailed chemistry tests to characterize the nuclear graphite (e.g., porosimetry, permeability, density, etc.). Operational measurements include continuous monitoring of the test assembly temperature and neutron flux. The helium flow rate and coolant impurities are measured daily.

TABLE 4.5

Limiting Test Conditions for SSL-1 Loop
1. Maximum Fast Fluence
$5.5 \times 10^{21} \mathrm{n} / \mathrm{cm}^{2} \quad(E>0.18 \mathrm{MeV})$
2. Fuel Particle Burnups
$10.5 \%$ for $(8 \mathrm{Th}, \mathrm{U}) \mathrm{O}_{2}$ fissile particles
$4.3 \%$ for $\mathrm{ThO}_{2}$ fertile particles
3. Steady State Maximum Fuel
$1200^{\circ} \mathrm{C}<\mathrm{t}<1300^{\circ} \mathrm{C}$ Temperature
4. Maximum Linear Fuel Rod Power Rating
191 watts/cm
5. Total 0xidant Impurity Level $10 \pm 3 \mathrm{vpm}$
6. Coolant pressure
$60 \pm 5 \mathrm{~atm}$ 
The postirradiation examination of SSL comprises extensive gamma-scan mass balances of the fuel element, the graphite plateout sleeve, and the metallic structures surrounding the fuel element. In addition, axial and radial fission product profile measurements are performed on a section of the fuel element and the graphite sleeve.

\section{3 .3 SAPHIR}

Purpose. The primary objective of the SAPHIR loop is to measure fission product deposition. This loop test is an endeavor of CEA and KFA in Pegase.

Test Configuration. SAPHIR is fueled with up to 14 AVR type fuel spheres and is operated with a fuel exit gas temperature of $2850^{\circ} \mathrm{C}$. Ten percent of the total loop coolant flow is passed through the fission product deposition experiment leg. The deposition tube in this circuit is $220 \mathrm{~mm}$ in diameter and $\sim 2$ meters long. There is a $90^{\circ}$ bend in the deposition tube section leaving the main loop. Previous deposition tubes have included ferritic and austenitic steels and Hastalloy. Maximum tube temperatures are typically $500^{\circ}$ and $600^{\circ} \mathrm{C}$. Future test runs include tubes made of Inconel 625, TZM and NIMONIC 8OA.

DIAMOND is a follow-on loop to SAPHIR, currently being designed for the Pegase reactor. It is designed to measure long term deposition studies of fission product diffusion into the circuit materials.

Test Measurements. HRB is the responsible organization for using SAPHIR data to validate fission product codes (primarily metallic release codes). No direct data collection or analysis will be carried out by GA. Liaison will be established with HRB to review their data analyses.

\subsection{CAPSULES}

A series of HTGR fuel test capsules have been and are being irradiated to study fuel particle and fuel rod performance characteristics. However, in addition to these objectives, capsules also offer an opportunity to verify 
fission product transport design methods. Through critical analyses of pretest, in-pile, and PIE measurements, predicted fission product migration behavior can be compared to measured values for capsules exposed to a variety of operating conditions (temperature, fast fluence, burnup).

On the basis of test configurations, irradiation histories, and accuracy of experimental measurements, the following capsules have been selected for analysis:

$F-30$

P130

$P \mid 3 R$

P13S

P13T

Capsules prior to F-30 or PI3Q were not selected for analysis for one or more of the following reasons:

1. In-pile measurements of fission gas $R / B$ were not made.

2. In-pile operating conditions of the capsule, in particular temperatures, were subject to large uncertainties.

3. PIE of the capsule had been completed and material discarded, making post-test measurements difficult or impossible.

In addition to studying the capsule tests listed, the code validation group will study data from later capsules and make design suggestions for future capsules in an effort to increase the usefulness of these irradiation tests.

Since there are similarities of design and validation data, the capsule studies are described in two groups, those capsules irradiated in the General Electric Test Reactor (GETR) (F-30, PI3R/S) and those irradiated in the Dak Ridge Reactor (ORR) (PI3Q, PI3T). 
4.4.1 F-30,P13R,P $13 S$

Purpose. These capsules, by virtue of their purged cell design, can be effectively utilized to validate the RAD code. In-pile R/B measurements from each purged cell of the capsules, in conjunction with temperature and fluence measurements, pretest $R / B$ and $P I E R / B$ and failed fraction measurements, will be utilized in the comparison of RAD code predictions with observed $R / B$ measurements.

Test Configuration and Conditions. Each capsule contains five $(F-30)$ or six (P13R, P13S) vertically aligned cells (see Fiq. 4.6). Each cell is individually purged with helium-neon gas mixtures which serve to regulate fuel temperatures as well as remove gaseous fission products. Temperatures are monitored with $C / A$ and $W / R e$ thermocouples. Four or five fuel rods, $1.24 \mathrm{~cm}$ diameter and of varying lengths, are aligned in series within graphite sleeve, which is placed within the metal test cell. (Selected center cells contain loose particle beds. Data from these cells will not be used per se for validation). Table 4.6 below provides a summary of particle characteristics, temperature, and fluence of each capsule studied in GETR. (16)

The cells will be exposed to temperatures and burnup similar to those expected for the HTGR. Since these two factors most strongly affect the failure fraction and fission gas release from heavy metal contamination in particle coatings, data gathered from these tests should be readily applicable to $R A D$ code validation.

Test Measurements. Data from pretest measurements should include metrology and $R / B$ measurements for each rod via TRIGA reactor irradiation. This data will allow accurate code input when the failed fuel fraction is known to be low. In-pile measurements include R/B ( $\sim 3$ week intervals), temperature, purge flow rate and composition, and estimates of fluence. This data should aid verification of the particle failure model utilized in RAD. In addition, data taken during power changes should aid predictions of thermal cycling effects. PIE measurements should include EOL R/B measurements on each rod, 


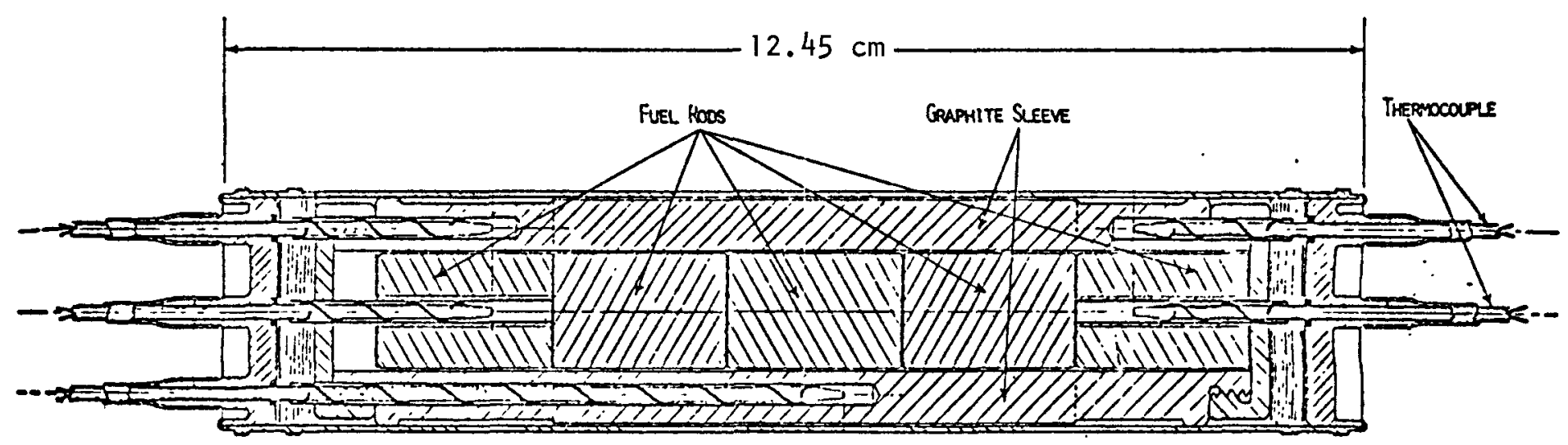

Fig. 4.6. Single cell from capsules irradiated in GETR. 
TABLE 4.6

Irradiation Conditions for Capsules Irradiated in GETR

\begin{tabular}{|c|c|c|c|c|c|c|}
\hline & \multirow{2}{*}{${ }^{\text {Temperature }}$} & \multicolumn{2}{|c|}{ Burnup, FIMA } & Fast Fluence & \multirow[b]{2}{*}{ Particle Design } & \multirow[b]{2}{*}{ Comments } \\
\hline & & Fissile & Fertile & $\mathrm{n} / \mathrm{cm}^{2} \quad(E>0.18 \mathrm{MeV})$ & & \\
\hline $\begin{array}{l}\text { P13R } \\
\text { PI3S }\end{array}$ & $\begin{array}{c}1050 \\
1050 \\
1250 \\
1075 \\
1075 \\
1300 \\
1075 \\
1075 \\
1500 \\
1075-1500\end{array}$ & $\begin{array}{c}20 \\
17 \\
15 \\
60-70 \% \\
60-70 \%\end{array}$ & $\begin{array}{l}6 \\
4 \\
2 \\
6 \%\end{array}$ & $\begin{array}{l}8 \times 10^{21} \\
6 \times 10^{21} \\
4 \times 10^{21} \\
5.5 \times 10^{21} \\
9.0 \times 10^{21} \\
6.5 \times 10^{21} \\
5.5 \times 10^{21} \\
9.0 \times 10^{21} \\
6.5 \times 10^{21} \\
5.5 \times 10^{21}\end{array}$ & 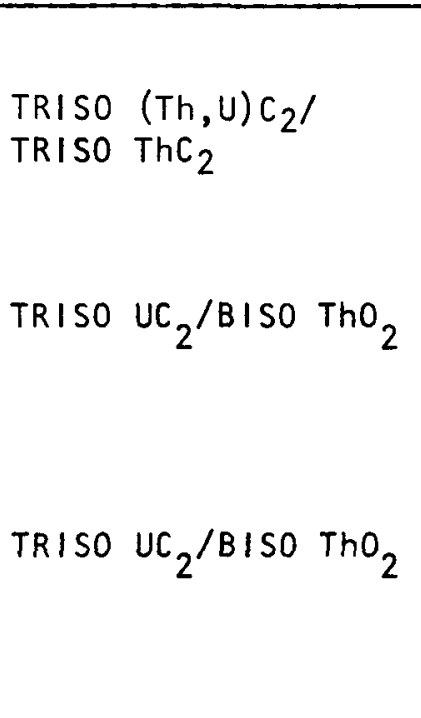 & $\begin{array}{l}\text { Thermal cycle } \\
226 \text { times }\end{array}$ \\
\hline
\end{tabular}


fluence at each position, burnup, particle failure fraction, and confirmation of temperatures. These measurements will permit code validation near capsule EOL operation by characterizing the variables during this period.

\subsubsection{P13Q,P13T}

Purpose. These capsules, by virtue of their purged capsule design and large HTGR geometry, can be employed to validate the RAD and FIPER codes. Fission gas release data, in conjunction with temperatures and fuel particle failure distribution, will be analyzed for RAD code validation. FIPER code validation will require measurement of mobile fission metal inventories, metallic profiles in graphite, sorption ratios, etc.

Test Configuration and Conditions. Each capsule contains three graphite fuel elements, $12.45 \mathrm{~cm}$ long, representative of an HTGR block, i.e., three fuel holes, $1.59 \mathrm{~cm}$ dia. and three "coolant" holes, $1.27 \mathrm{~cm} \mathrm{dia.,} \mathrm{arranged}$ symmetrically about a fourth "coolant" hole. Each isotropic H-45l graphite element holds six $1.55 \mathrm{~cm}$ diameter by $5.04 \mathrm{~cm}$ long fuel rods, making a total of 18 rods under study. The central "coolant" hole is in actuality a graphite spine containing thermocouples, dose assemblies, and the capsule purge tube. The remaining "coolant" holes are slots used for piggyback sample irradiation. Fuel temperatures are maintained by passing He-Ne mixtures between the outer surface of the graphite fuel element and the capsule wall, which also serves to sweep out fission gases. As such, negligible coolant sweeps through the "coolant" holes. Temperatures are monitored with C/A and W/Re thermocouples within and adjacent to fuel rods. See Fig. 4.7. Both capsules are designed to operate isothermally in ORR at peak fuel rod temperatures of $1150^{\circ} \mathrm{C}$ and with maximum fast neutron fluences of $9 \times 10^{21} \mathrm{n} / \mathrm{cm}^{2}$. PI3Q is being used to demonstrate the performance of HTGR fuel rods fabricated using candidate processes and materials. PI3T is being utilized principally to verify the "cured-in-place" concept for HTGR fuel rods. See Table 4.7.

Since both capsules are designed to simulate HTGR plant operating conditions, fission gas release data should be readily applicable to. RAD code validation. Fission metal release data from the capsules are not immediately applicable to FIPER code validation because: 


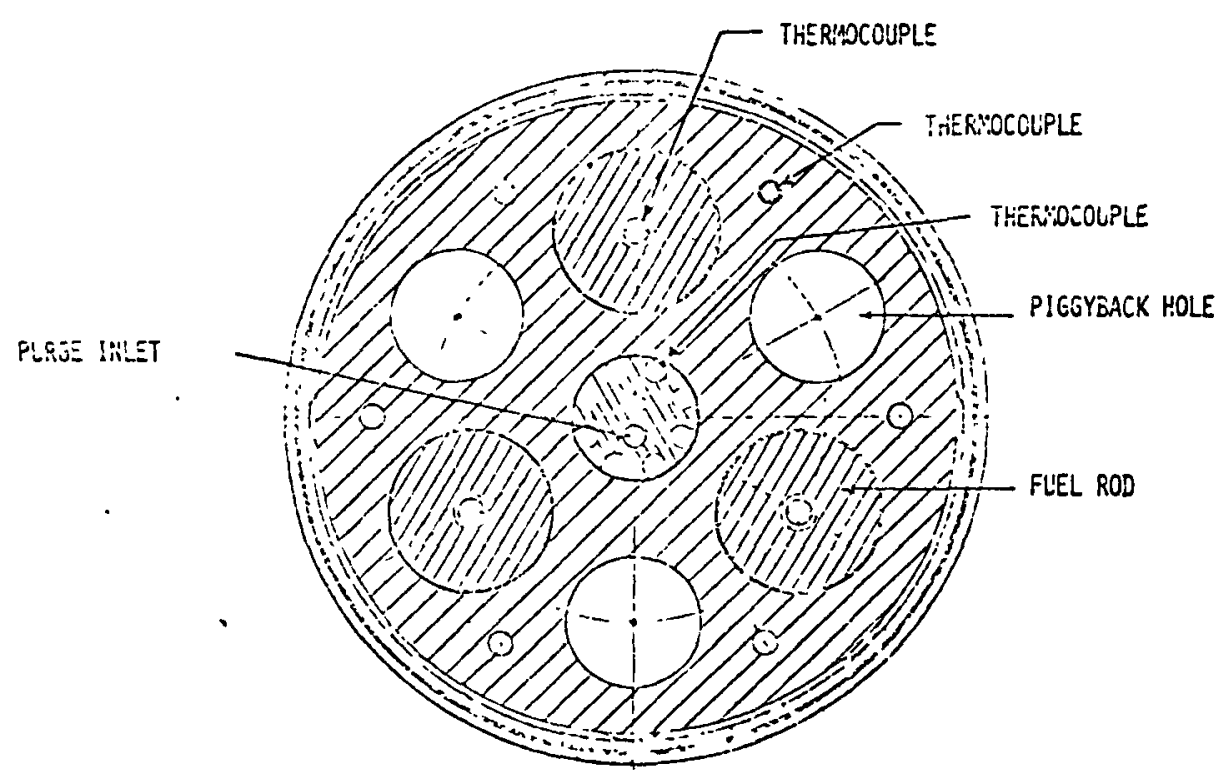

a

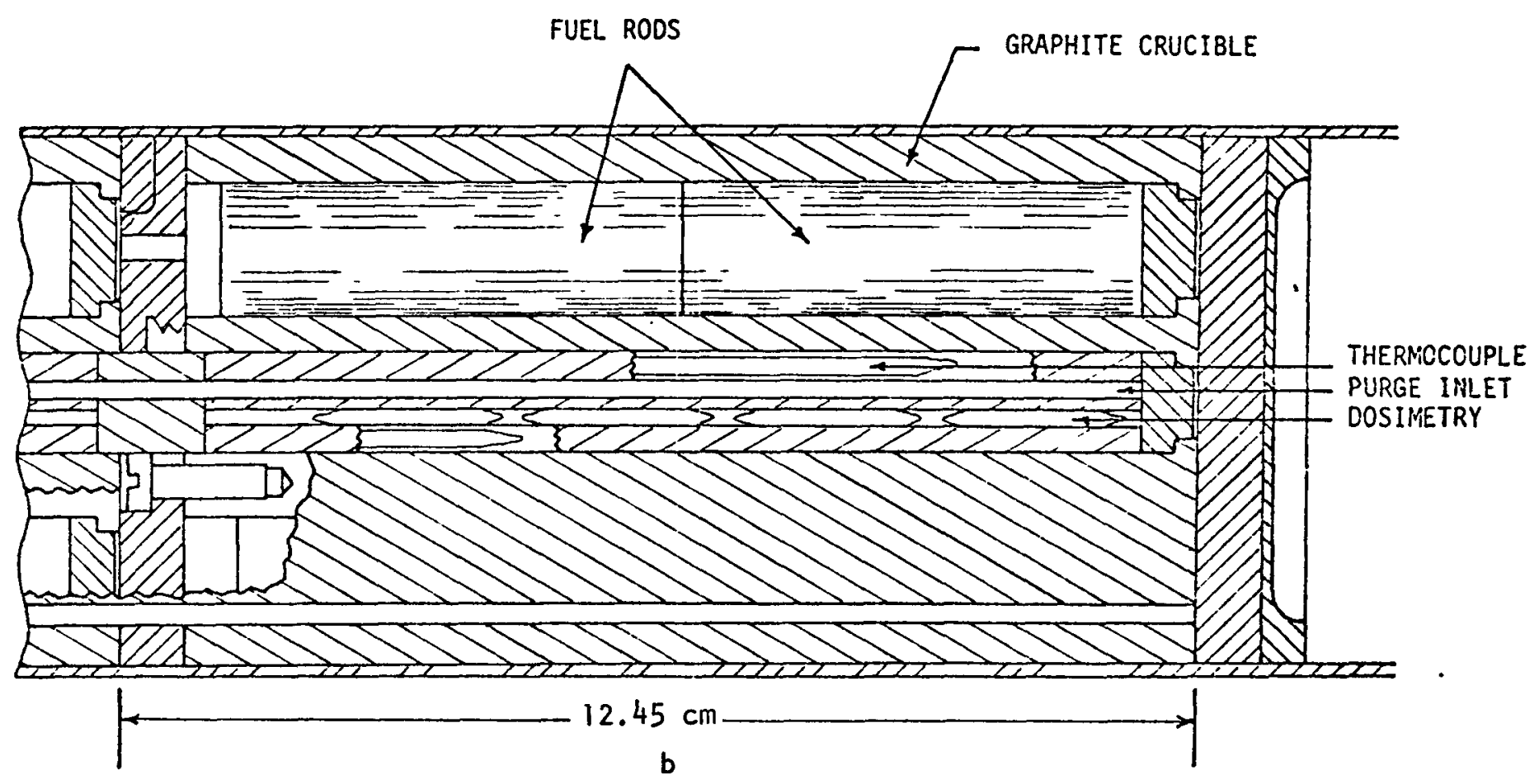

Fig. 4.7. Capsules irradiated in ORR

a) Cross section

b) Single fuel rod region 
TABLE 4.7

Irradiation Conditions for Capsules Irradiated in ORR

\begin{tabular}{|c|c|c|c|c|c|c|}
\hline & \multirow{2}{*}{$\begin{array}{c}\text { Temperature } \\
{ }^{\circ} \mathrm{C}\end{array}$} & \multicolumn{2}{|c|}{ Furnup, FIMA* } & Peak Fast Fluence & \multirow{2}{*}{ Particle Design } & \multirow{2}{*}{ Comments } \\
\hline & & Fissile & Fertile & $\mathrm{n} / \mathrm{cm}^{2} \quad(E>0.18 \mathrm{MeV})$ & & \\
\hline$P 130$ & 1150 & $60-70$ & 6 & $9 \times 10^{21}$ & TRISO UC ${ }_{2}$ /BISO $\mathrm{ThO}_{2}$ & $\begin{array}{l}\text { HTGR candi- } \\
\text { date pro- } \\
\text { cesses and } \\
\text { materials }\end{array}$ \\
\hline P13T & 1150 & $60-70$ & 6 & $9 \times 10^{21}$ & TRISO UC ${ }_{2}$ /BISO $\mathrm{ThO}_{2}$ & $\begin{array}{l}\text { Cured-in- } \\
\text { place fuel } \\
\text { rods }\end{array}$ \\
\hline
\end{tabular}


1. The capsules do not operate under high pressure, high coolant flow conditions, and the "coolant" holes do not act as sinks for fission metals.

2. Large thermal gradients exist near the outer circumference of the capsules, affecting diffusion coefficients, sorption ratios, and fission metal distribution.

To use capsule data for FIPER code validation will require close modeling of the capsule configuration within the constraints of the one-dimensional model utilized in FIPER. In an effort to make the capsule data more representative of HTGR operating conditions, a $1.23 \mathrm{~cm}$ diameter $\times 5.04 \mathrm{~cm}$ long char-loaded graphite rod $(H-451)$ has been submitted for insertion in a piggyback slot in PI3T. It is hoped the high sorptivity graphite will act as an effective sink for mobile fission metals and, thus, more nearly represent a swept coolant hole of an HTGR fuel block. Such modifications are anticipated in future capsule designs to broaden the objectives of the irradiation program to include in-pile verification of fission product transport phenomena.

Test Measurements. BOL, operating, and EOL measurements, analogous to the GETR capsule measurements, will be undertaken. This data will allow verification of the RAD code and its input assumptions, including the particle failure model (the effects of temperature and burnup).

An additional series of measurements will be performed to aid FIPER predictions. These include metallic mass balances (including metallic plateout in purge lines), metallic profiles in graphite, sorption ratios for rod and graphite, and metallic inventories. This data will provide important validation of laboratory anneal test data and will be required to effectively validate FIPER (providing "low flow" coolant conditions can be modeled). 


\subsection{FUEL TEST ELEMENTS}

A series of 33 fuel test elements (FTE) have been irradiated in the Peach Bottom reactor. FTEs have been designed to study the irradiation behavior of a wide variety of fuel designs, including FSV reference fuel, candidate HTGR fuel, cured-in-place fuel rods, etc. In addition, eight FTEs were fitted with center-spine samples utilized to study the irradiation behavior of selected graphite specimens, loose particle beds, mobile fission metals, etc. A brief summary of the salient features of the FTEs is shown in Table 4.8. A brief review of the table reveals that at tempts will be made to use data from all "purge gas sampled" FTEs, including those containing center-spine samples, to validate the RAD code. In addition, validation of the FIPER code will be undertaken utilizing data from FTE-16 (provided PIE is carried out).

\subsubsection{Purge Gas Sampled FTEs}

Purpose. Data from purge sampled FTEs will be used to aid validation of the RAD code. In-pile measurements yield the average $R / B$ of all fuel in the element. By entering pretest R/Bs, temperature, fuel particle coating failure, and flux distributions in the RAD code, comparison of calculated and measured results can be undertaken.

Test Configuration and Conditions. The fuel test elements have the same configuration as driver elements with the exception of the arrangement of the fuel. Fuel compacts are replaced by graphite crucibles drilled in a 6- or 8-hole "teledial" arrangement. FSV or HTGR type fuel rods are fitted into the holes in an arrangement analogous to HTGR core fuel element design. The purge flow from each "purged FTE" is sampled by means of a sampling tube positioned within the FTE near the standoff pin with accompanying lines leading to a sampling board. Fission gas release is monitored on an intermittent basis. 
TABLE 4.8. Summary of FTE Salient Features

\begin{tabular}{|c|c|c|c|c|c|c|c|c|}
\hline No. & Temp. & Purge & P.I.E. & $\begin{array}{l}\text { Spine } \\
\text { Samples }\end{array}$ & Sponsor & Configuration & Validate & Comments \\
\hline FTE-I & Yes & No & $\begin{array}{l}\text { Near } \\
\text { Completion }\end{array}$ & Yes & GA & $\begin{array}{l}\text { 8-Hole } \\
\text { Teledial }\end{array}$ & No & Blended bed fuel LHTGR \\
\hline-2 & Yes & No & $\begin{array}{l}\text { Near } \\
\text { Completion }\end{array}$ & Yes & $\mathrm{GA}$ & $\begin{array}{l}\text { 8-Hole } \\
\text { Teledial }\end{array}$ & No & Blended bed fuel LHTGR \\
\hline-3 & Yes & No & Complete & $\overline{Y e s}$ & $\overline{A E C}$ & $\begin{array}{l}\text { 8-Hole } \\
\text { Teledial }\end{array}$ & No & FSV fuel rod geometry LHTGR \\
\hline-4 & Yes & No & $\begin{array}{l}\text { Near } \\
\text { Completion }\end{array}$ & Yes & $\overline{A E C}$ & $\begin{array}{l}\text { 8-Hole } \\
\text { Teledial }\end{array}$ & No & FSV fuel rod geometry LHTGR \\
\hline-5 & Yes & No & $\begin{array}{l}\text { In } \\
\text { Preparation }\end{array}$ & Yes & GA & $\begin{array}{l}\text { 8-Hole } \\
\text { Teledial }\end{array}$ & No & $\begin{array}{l}\text { FSV fuel rod geometry LHTGR } \\
\text { cured in place }\end{array}$ \\
\hline-6 & Yes & No & $\begin{array}{l}\text { In } \\
\text { Preparation }\end{array}$ & Yes & $\overline{A E C}$ & $\begin{array}{l}8 \text {-Hole } \\
\text { Teledial }\end{array}$ & No & FSV fuel rod geometry LHTGR \\
\hline-7 & Yes & Yes & No & No & $\overline{G A}$ & $\begin{array}{l}\text { 8-Hole } \\
\text { Teledial }\end{array}$ & $\begin{array}{l}\text { Yes } \\
\text { RAD } \\
\end{array}$ & Fuel rods LHTCR \\
\hline-8 & Yes & Yes & No & No & GA & $\begin{array}{l}\text { 8-Hole } \\
\text { Teledial }\end{array}$ & $\begin{array}{l}\text { Yes } \\
\text { RAD } \\
\end{array}$ & Fuel rods LHTGR \\
\hline-9 & Yes & Yes & No & No & $\overline{G A}$ & $\begin{array}{l}\text { 8-Hole } \\
\text { Teledial }\end{array}$ & $\begin{array}{l}\text { Yes } \\
\text { RAD }\end{array}$ & Fuel rods LHTGR \\
\hline $\begin{array}{r}-10 \\
(\text { PTE-3) }\end{array}$ & Yes & Yes & No & No & GA/PSC & $\begin{array}{l}\text { 8-Hole } \\
\text { Teledial }\end{array}$ & $\begin{array}{l}\text { Yes } \\
\text { RAD }\end{array}$ & FSV partlcles $\&$ rods \\
\hline$(\mathrm{RTE}-1)$ & No & No & ORNL & No & $\begin{array}{l}\text { ORNLT } \\
\text { AEC }\end{array}$ & $\begin{array}{l}\text { 8-Hole } \\
\text { Teledial }\end{array}$ & No & $\begin{array}{l}\text { Cured-in-place, cured-in-holder } \\
\text { recycle }\end{array}$ \\
\hline-12 & Yes & No & No & No & $\mathrm{GA} / \overline{\mathrm{PSC}}$ & $\begin{array}{l}\text { 8-Hole } \\
\text { Teledial }\end{array}$ & No & Fuel rods LHTGR \\
\hline-13 & Yes & No & ORNL & No & GA/EPRI & $\begin{array}{l}\text { 8-Hole } \\
\text { Teledial }\end{array}$ & No & Pu fuel study \\
\hline-14 & Yes & Yes & $\begin{array}{l}\text { Near } \\
\text { Completion }\end{array}$ & Yes & GA/AEC & $\begin{array}{l}\text { 6-Hole } \\
\text { Teledial }\end{array}$ & $\begin{array}{l}\text { Yes } \\
\text { RAD }\end{array}$ & Fuel rods LHTGR \\
\hline-15 & Yes & Yes & $\begin{array}{l}\text { In } \\
\text { Preparation }\end{array}$ & Yes & GA/AEC & $\begin{array}{l}\text { 6-Hole } \\
\text { Teledial }\end{array}$ & $\begin{array}{l}\text { Yes } \\
\text { RAD }\end{array}$ & Fuel rods LHTGR \\
\hline $\begin{array}{r}-16 \\
(\text { PTE }-4) \\
\end{array}$ & Yes & Yes & $?$ & No & GA/PSC & $\begin{array}{l}\text { 8-Hole } \\
\text { Teledial }\end{array}$ & $\begin{array}{c}\text { Yes } \\
\text { RAD FIPER } \\
\end{array}$ & FSV fuel \\
\hline $\begin{array}{r}-17 \\
(P T E-5)\end{array}$ & Yes & Yes & No & No & GA/PSC & $\begin{array}{l}\text { 8-Hole } \\
\text { Teledial }\end{array}$ & $\begin{array}{l}\text { Yes } \\
\text { RAD } \\
\end{array}$ & FSV D fuel \\
\hline-18 & Yes & No & Yes & No & $\begin{array}{l}\text { KFA/GAT } \\
\text { HOBEG }\end{array}$ & Molded Block & No & $\begin{array}{l}\text { Molded block pebble bed } \\
\text { technology }\end{array}$ \\
\hline $\begin{array}{r}\mathrm{FBTE} \\
1-6\end{array}$ & Yes & No & No & No & GA & $\begin{array}{l}\text { 8-Hole } \\
\text { Teledial }\end{array}$ & No & Fuel rods $\&$ blended bed LHTGR \\
\hline $\begin{array}{r}\text { RTE } \\
2-8 \\
\end{array}$ & No & No & ORNL & No & $\begin{array}{l}\text { ORNL/ } \\
\text { AEC }\end{array}$ & $\begin{array}{l}\text { 8-Hole } \\
\text { Teledial }\end{array}$ & No & $\begin{array}{l}\text { Cured-in-place, cured-in-holder } \\
\text { recycle }\end{array}$ \\
\hline PTE-2 & Yes & No & Complete & No & GA/PSC & $\begin{array}{l}\text { Hex. } \\
\text { Arrangement }\end{array}$ & No & Cured-in-place FSV fuel rods \\
\hline
\end{tabular}


Test Measurements. To obtain meaningful data for validation of RAD from FTEs, reliable temperature and power readings, and fuel particle failure fractions must be supplied as a function of fuel position. This is particularly important for FTE-7, 8, 9, 10 and 17, where no PIE is planned, and thus, no postirradiation measure of $R / B$ of individual rods or local failure fraction will be available. Thus, for all elements except FTE-14, 15, 16, only initial FTE operation, where in-service fuel particle coating failure can be assumed to be negligible, will be used to validate gaseous fission product release codes. When PIE of FTE-14, 15, and 16 is completed (if PIE of FTE-16 is carried out), EOL operation can be validated as well as $B O L$. Also, the contribution to fission gas release from center-spine samples irradiated within FTE-14, 15 will have to be estimated from PIE of the loose particle beds.

Data from pretest measurements should include metrology $R / B$ of representative fuel rods. In-pile measurements include R/B of fission gases, temperatures, reactor power level, and purge flow rate. PIE is planned for FTE-14, 15 and 16 only.

\subsubsection{FTE-16}

Purpose. FTE-16 will be examined to aid validation laboratory anneal test data used as input to FIPER, as well as validation of FIPER itself. PIE inplle operating data will allow comparison of predicted release characteristics and observed behavior.

Test Configuration and Conditions. See Section 4.5.1. It should be noted that FTE-16 has no center-spine samples. As a result, prediction of metal profiles in the spine can be directly compared with PIE measurements.

Test Measurements. See Section 4.5.1. PIE measurements should include EOL R/B measurements on selected rods, including samples from all types of fuel particle design $(H, A, A A, B, D)$, fluence at each axial position, particle 
failure fraction on selected rods, burnup, metrology, confirmation of temperatures, fission metal inventories, mass balance, sorption ratios, and metallic profiles in graphite.

\subsection{CONTRIBUTIONS}

\subsubsection{Fort St. Vrain}

The Fort St. Vrain reactor will be an operating HTGR with the design closest to that of the large HTGR, including comparable core geometry, fuel, graphite and coolant temperatures, coolant pressure, etc. Accurate prediction of fission product behavior in FSV should be a convincing demonstration of the applicability of validated fission product transport codes.

As mentioned, FSV will be the principal verification test for the RAD code. Indeed, it will unquestionably verify our design methods for predicting gaseous fission product inventories. This verification data will be obtained at the time of initial full power operation. Fort St. Vrain initial core fuel elements are as well characterized with respect to fission gas release as any core is likely to be. The location of each fuel element in the core and the service limit of each fuel has been carefully defined. Most importantly, early $R / B$ measurements recorded at full power operation will not be affected by in-service failure of fuel particle coatings. Thus, no calculation of fuel particle coating failure distribution will be required, and calculations of power and temperature distribution can be used to predict the release rates of gaseous fission products from the core. 


\subsubsection{Peach Bottom}

The Peach Bottom reactor is unique because of its eight year operating history, including three years of operation with core 2 fuel elements. This length of irradiation is much longer than that of capsules ( 212 months) and loops (2-12 months). Because of the similarity of metallic components and the extended period of operation at representative HTGR operating conditions, Peach Bottom will serve as the principal test used to validate the PAD code. Indeed, it is unlikely that PAD can be validated without an extensive Peach Bottom circuit examination program conducted during decommissioning.

PIE measurements on driver elements carried out at ORNL will serve as further confirmation of metallic fission product release predictions carried out on individual Peach Bottom fuel elements.

\subsubsection{CPL}

The CPL series of loop tests are the primary tests to validate metallic fission product transport design methods - the FIPER code. CPL 2 thoroughly monitors the transport properties of all fission products, in particular the metallic elements. Hence, with known source terms (particle coating failure fraction), known material properties, and complete mass balances, FIPER code will be validated. Lessons learned from these tests will be supplied to predictions of metallic release from Peach Bottom and FSV.

In the CPL $2 / 1$ experiment, codes will be validated at limiting HTGR design conditions. The CPL $2 / 3$ experiment will determine the effect of coolant impurities on fission product migration. Additionally, dust is expected to be formed during this test and aerosol transport will be studied. CPL $2 / 4$ will be a measure of fission product release during coolant depressurization and "cook-out". While the primary purpose of the CPL 2 series of test is to determine metallic specie release from fuel elements, substantial information will be obtained concerning the distribution of radionuclides in the primary coolant circuit, i.e., PAD code verification, via studies of deposition, dust, reentrainment, and associated radioactivity. The CPL 2 
series of experiments contain five different metal materials similar to those present in the HTGR heat exchanger. Thus, sorption and desorption properties of fission product metals on circuit materials will be measured. CPL 2 series of tests sèrve as the primary backup verification tests for the PAD code.

\subsubsection{SSL}

The benefits of SSL-1 loop testing are the same as those of CPL 2 loop testing with the important additional feature that the effect of enhanced sorptivity on metallic release will be measured. SSL-1 test accumulated a fast neutron fluence $(E>0.18 \mathrm{MeV})$ of $\sim 5 \times 10^{21}$. This is expected to cause the fuel element graphite to be more adsorptive, thus causing the fuel element itself to act as a sink. Analysis of this effect will make important contribution to development.

Gaseous release from the fuel element of SSL-1 was monitored with time. This data shows pulses of increased activity, apparently resulting from release of fuel particle inventory following fuel particle coating failure. Analysis of this data will be important in formulation of new RAD code models which correctly account for this phenomena.

\subsubsection{Capsules}

Capsules are of particular importance in validating code input assumptions since temperature, burnup, fluence, and particle failure fraction are well characterized during irradiation. Thus, data from all of the capsules will aid verification of RAD code assumptions, including $R / B$ dependence on temperature (thermal cycling data as well as steady-state data), burnup, and fluence. In addition, the same methods utilized in large HTGR design will be used to predict gaseous releases for comparison with in-pile measurements.

Detailed fission product analyses of capsules have not been carried out in the past. Studies of $\mathrm{P} 13 \mathrm{Q}$ and $\mathrm{P} 13 \mathrm{~T}$, which contain a representative portion of the graphite fuel element, will serve as in-pile confirmation of laboratory anneal tests which model metallic diffusion. 
4.6.6 Fuel Test Elements (FTE)

Principal contributions of fuel test element studies will be further verification of FIPER via analysis of graphite sleeve and spine metallic profiles, and evaluation of temperature effects for validation of RAD code input assumption.

\subsubsection{Summary}

Table 4.9 presents a listing of the anticipated contributions of each test to the validation of the three transport codes. 
TABLE 4.9

Principal Contributions of Each Validation Test

Gaseous Radionuclides (the RAD Code)

Contribution

1. Fort St. Vrain

Operating reactor. Best validation;

initial full power in-service failure distribution $\approx 0$, so sources of fission gases will be well defined.

2. SSL

Evaluate release of inventory following particle coating failure.

3. Capsules

Evaluate temperature dependence of release; burnup effects; burst effects; thermal cycling effects.

4. Peach Bottom purge stream

Operating reactor. examination

5. FTE

Temperature dependence of release.

Metallic Radionuclides (the FIPER and TRAFIC Codes)

1. $\mathrm{CPL} 2 / 1,2 / 3$

Monitor release from small volume of fuel.

2. $S S L$

Evaluate effect of increased sorptivity on release.

3. Peach Bottom fuel element

Operating reactor. examination

4. FSV

Operating reactor

5. Capsules

6. Fuel test element

Extent and distribution unknown.

7. Foreign test facilities*

\section{Circuit Radioactivities (the PAD Code)}

1. Peach Bottom circuit examination

Operating reactor, long term operation with HTGR materials and at HTGR operating conditions.

2. CPL $2 / 1,2 / 3,2 / 4$

$\left\{\begin{array}{l}\text { Short term tests of similar HTGR } \\ \text { metal materials at near HTGR } \\ \text { operating conditions. }\end{array}\right.$

4. FSV

Operating reactor.

"Validation work to be done by other organizations (directed principally toward metallic species migration).

AVR reactor

SAPHIRE IOOP 


\section{CODE VALIDATION SCHEDULES}

Figures 5.1 through 5.3 show the validation schedules for the RAD, FIPER, and PAD codes. These schedules were assembled by examination of each individual test validation plan. The points represent the completion of final analyses with the current codes. These points were fitted to the timeline for validation of each code. The Fuel Methods Department code improvement schedule is also included for each code. All codes have the target validation date of June 1977, to allow time for predictions to be made for the Delmarva FSAR due to be issued in early 1978. 
$2-5$

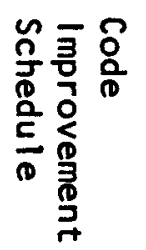






$\varepsilon-\varsigma$
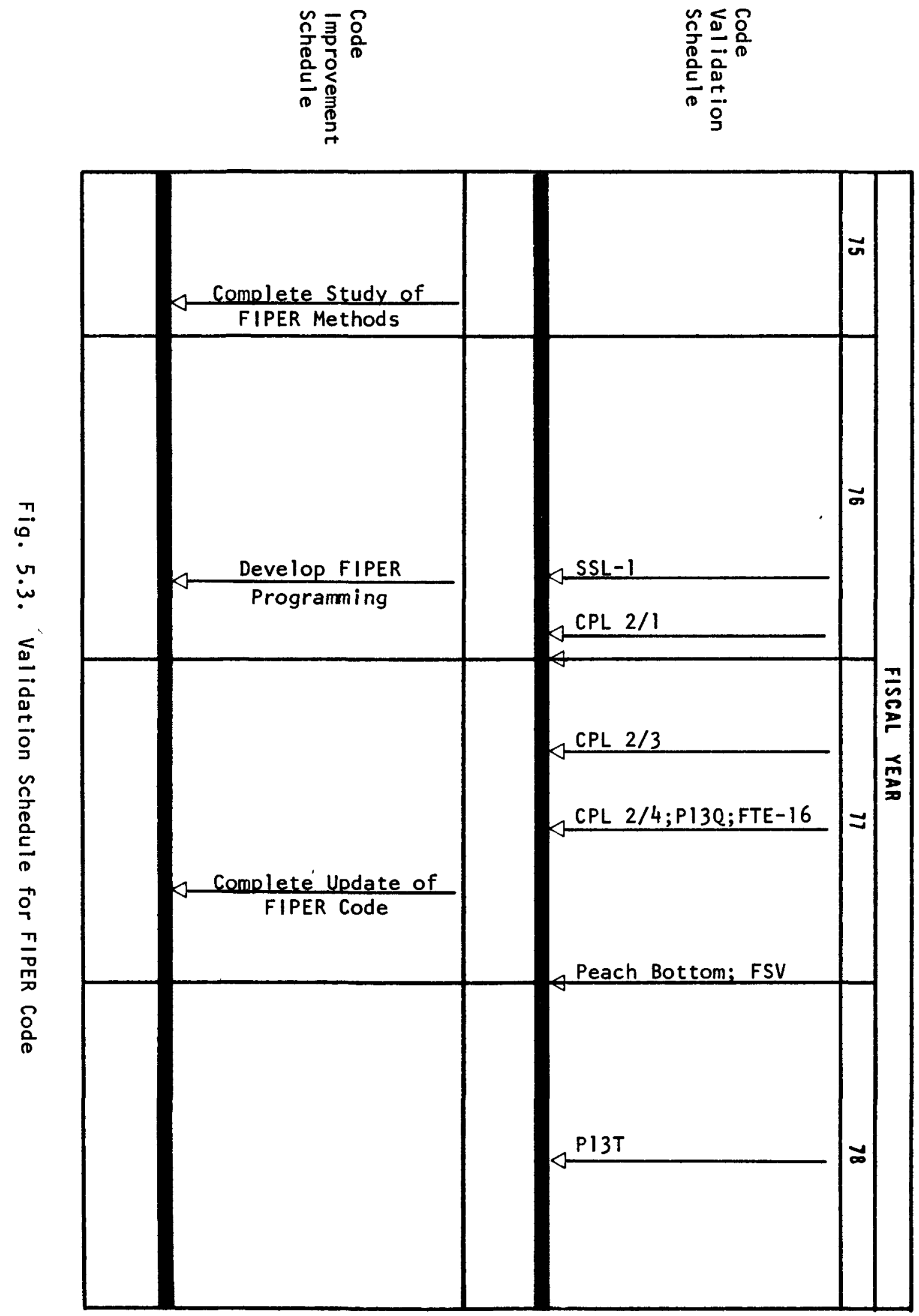
$7-5$

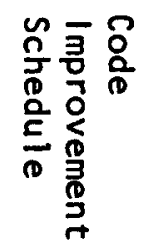

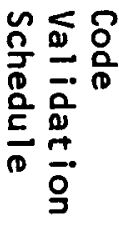

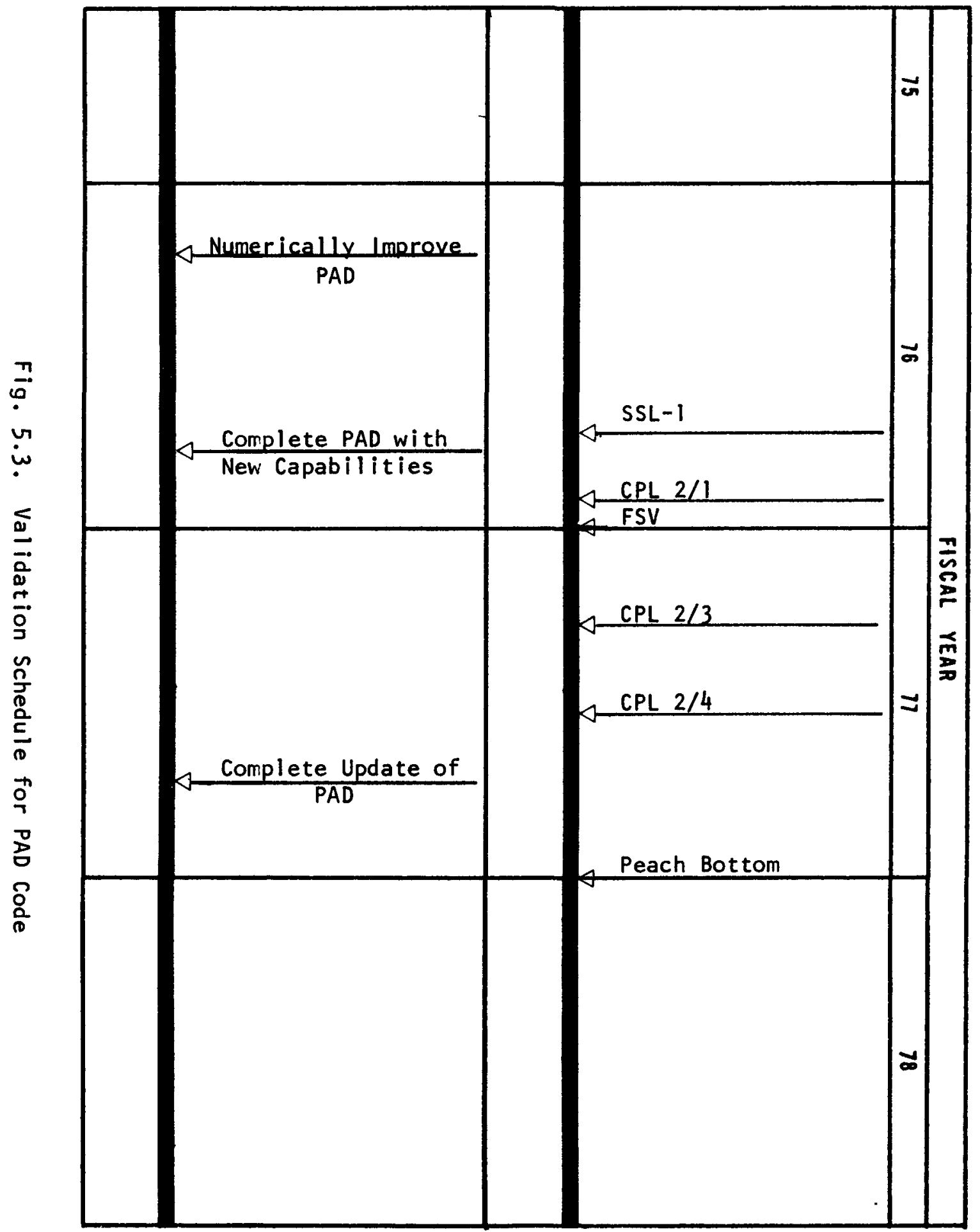




\section{STATUS OF RAD CODE VALIDATION}

The accuracy of the mathematics of fission product transport computer programs has been routinely verified during initial code development. However, the accuracy with which basic transport equations utilized in the codes represent transport phenomena has not been extensively tested. As discussed previously in Section 2.2 , experimental confirmation of release models has been confined to studies concerning the validity of individual phenomena, i.e., differential studies in the laboratory, rather than verification of the complete transport model, i.e., integral measurements.

\subsection{RAD}

Gaseous fission product release studies of irradiated fuel rods and capsules have provided input data for the RAD code. RAD has never been used to analyze experimental release measurements from fuel test elements, loops, or reactors.

\subsubsection{Differential Tests}

To date, the major area of interest has centered on determining the fuel particle failure fraction and fission gas release (R/B) from failed particles. A substantial amount of work has been directed towards examining the fission gas release dependence on temperature, burnup, fluence and failed fuel geometries in irradiated fuel rods and capsules containing HTGR fuel.

The majority of differential type tests are $R / B$ measurements carried out in the TRIGA reactor. Samples of intact particles, failed particles, fuel rods, etc. are positioned within a resistively heated king furnace capable of maintaining in-pool sample temperatures from $900^{\circ}$ to $1600^{\circ} \mathrm{C}$. Studies are carried out to measure fission gas release as a function of

$\sqrt{T_{1 / 2}}$ (the idealized half-life dependence of $R / B$ ) for selected $f$ ission gases. In addition, the effects of burnup and fluence have likewise been studied in TRIGA via the irradiation of particles and rods previously 
irradiated in capsules and FTEs. Burnup as percent FIMA (fissions in metal atoms) has been found to have little effect on measured $R / B$ of intact particles. Fluence and burnup effects are manifest in the particle failure model utilized in the RAD code by assuming particle failure fraction (with the accompanying release of inventory) increases linearly with fluence. The dependence of $R / B$ on fuel geometry has been extensively studied in TRIGA, as is shown in Table 6.1.

\section{1 .2 Integral Tests}

Fission gas fractional release measurements have been made on a number of irradiated capsules, loops, and test elements containing HTGR fuel. The parameter measured has been curies of gaseous radionuclide release. Attempts to relate this gross released activity to power, temperature, fuel particle coating failure fraction, burnup, or neutron fast fluence distributions in these capsules, loops, or test elements have never been made.

To date, the RAD code validation procedure has utilized information principally from the differential tests. Fission gas release dependence on temperature, fluence, burnup, etc. as measured in the TRIGA tests was applied to the total fission gas release volume measured in the integral tests. The net predicted release was then compared to the measured values. Consequently, since the differential inputs to the RAD code have never been verified for large sources of fission gas released from test elements, loops or reactors, the RAD code has never been fully validated.

\subsection{FIPER}

Limited efforts have been made to verify the metallic release codes using the contemporary release model.

\subsubsection{Differential Verification Tests}

The bulk of validation work to date has been restricted to efforts to

prove the fundamental assumption of metallic transport codes; i.e., metallic 
TABLE 6.1

Fission Gas Release Data for Various Failed Fuel Concepts

$\mathrm{Kr}-85 \mathrm{~m}(\mathrm{R} / \mathrm{B})_{\mathrm{f}}$ at $1100^{\circ} \mathrm{C}$

\section{Contamination}

Loose $\mathrm{UO}_{2}$ powder in fuel rod

$\sim 0.50$

$U$ diffused into carbon matrix

$\sim 0.30$

Bare Fuel Kernels

Packed bed of $\mathrm{UO}_{2}$ kernels - no carbon matrix

0.002

Packed bed of $\mathrm{UO}_{2}$ kernels with carbon matrix

0.01

Bare kernels in fuel rod $\left(\mathrm{UO}_{2}\right.$ or $\left.U \mathrm{C}_{2}\right)$

0.04

Failed Particles, unconstrained

Mechanically cracked BISO or TRISO $\mathrm{UO}_{2}$ or $\mathrm{UC}_{2} \quad 0.02$

Loose particles failed in-pile, PI3N capsule 0.02

Failed Particles, constrained

Pluto $3 A$ loop, $F=0.2 *$

0.005

GA capsule 309 series, $F=1.0$

0.005

GA capsule $6 F 2$ series, $F=0.25-1.0$

0.004

GA GAIL IIIA loop, $F=1.0$

0.002

GA GAIL 111B loop, $F=1.0$

0.005

Peach Bottom Core 1, F $=0.8$

0.008

GAIL IV loop, $F=0.008$

0.006

Fuel rods, $P 13 \mathrm{~N}$ capsule, $F=0.25$

0.002

Laser-pinhole failed $\mathrm{BISO}_{\mathrm{UO}_{2}}$ or $\mathrm{UC}_{2}$

0.007

${ }^{*} F=$ failed fraction. 
fission product migration can be represented as Fickian transport across a concentration gradient. It is clear that this is a valid assumption for most metallic species, but as a result of recent analyses of laboratory data, it is not evident that it is a valid assumption for cesium.

Peach Bottom fuel test element No. 3 (FTE-3) contained strontium, barium, samarium, and cesium diffusion samples in a center-spine position. The purpose of these experiments was to obtain transport properties of these fission products in graphite and in an in-pile environment as a function of concentration and temperature. Fission product concentration profiles were obtained from radial sections of the center spine diffusion sample crucibles. Examination of the profiles indicated that strontium and barium exhibited classical (Fick's law) type behavior while samarium behavior was predominantly of the classical type. Cesium profiles, however, showed a fast component which did not correspond to a Fick's law transient diffusion behavior. There was also an indication of a slow component in the cesium profiles. It was concluded that the fast component of cesium transport is likely due to inpore surface diffusion of atoms. This transport model, of course, differs from the reference design method.

Norman and Chandra $(18)$ have conducted extensive laboratory studies directly toward defining cesium transport across the graphite web. They concluded that a simple Fickian model is not an appropriate representation of cesium diffusion. As a result of this work, they have been proponents of a non-Fickian grain-boundary diffusion model which enables a simultaneous interpretation of cesium currents (atoms $/ \mathrm{cm}^{2}-\mathrm{sec}$ ) and cesium concentration profiles. The grain boundary diffusion model consists of two diffusion coefficients: a "fast path" or surface diffusion coefficient and a "bulk" coefficient. Norman and Chandra have concluded that diffusion sample loading is controlled by the slow bulk diffusion coefficients, whereas the rate of release is controlled by the "fast path" diffusion coefficient. Thus, dependence upon concentration profiles for interpreting transport phenomena is tenuous. Transport experiments in which measurement of the flux of atoms released for the sample as well as concentration profiles are determined are the only reliable means for studying cesium transport phenomena. 
Mysels (19) has continued the cesium transport studies of Norman and Chandra. Mysels' experiments show significant differences in flux from samples present in different atmospheres (helium, hydrogen, and carbon monoxide). Reproducibility of laboratory results is a problem because of insufficient definition of the residual atmosphere during sample preparation. Thus, the replication of an HTGR environment in the laboratory involves more than the absence of a neutron environment. This problem reemphasizes the need for reactor experiments.

Many other differential measurements are made besides those which measure transport across the graphite web. Vapor pressure measurements of metallic species on both graphite and fuel rod matrix material are an important input in the calculations. Also, considerable laboratory work has been conducted to obtain fuel particle release measurements (diffusion coefficients). All this data invariably assumes a priori a model representing transport across the barrier being investigated. Individually, these models may accurately represent transport across particular barriers, but they have not been extensively tested as a system of barriers in integral tests.

Presently, there is no generally accepted model for representing cesium transport through graphite. One of the primary purposes of this validation program is to calibrate design method cesium release with observed values.

\subsubsection{Integral Verification Tests}

FREVAP- 8 code calculations of metallic fission products released from fuel elements have been compared to observed releases in PLUTO 8 and 15 loops at Harwell for Dragon Project and in General Atomic (GAIL) loop in GETR at Vallecitos. (20) FREVAP codes were the forerunner of the presently used design codes FIPER and TRAFIC. Like FIPER and TRAFIC, the FREVAP code contained the metal adsorption isotherms. However, unlike the FIPER code which has capabilities of modeling operating transients, the FREVAP code assumed that migration through fuel free graphite webs which separate HTGR fuel from its helium coolant could be represented by steady-state diffusion equations. 
The results of this specific validation exercise indicated calculated strontium released was more than 100 times that observed. For the shortlived Ba-140 the situation was reversed because the calculation predicted that effectively all Ba-140 would decay during passage through the graphite, whereas in reality, there is a small release of $\mathrm{Ba}-140$ as $\mathrm{Xe}-140$. It was concluded that estimates of release using FREVAP code were quite conservative. Primarily as a result of this demonstrated conservatisms, FIPER codes that account for transient behavior were developed.

FIPER code has been tested against Peach Bottom reactor operation. (9) The exercise dealt primarily with attempts to deduce diffusion coefficients of strontium and cesium by matching predicted and measured concentration profiles. FIPER code duplicated cesium concentration profiles in Peach Bottom Core 1 fuel element sleeve and spine with accuracy. Figure 6.1 gives an example of this fit for the sleeve at fuel compact position 9. Figure 6.2 shows FIPER code predicted and observed concentration profiles in the spine at compact position 9. In the latter figure, Sr-90 experimental data was first "fitted". Then, by simply changing the decay constant to that of $\mathrm{Kr}-89$, the $\mathrm{Sr}-89$ curve was matched to that shown. This indicates that the strontium profiles resulted from the decay of its noble gas precursors and that transport of directly produced strontium was below detectable limits. Using reference design data and reference assumptions, provisional predictions of cesium release from Peach Bottom is approximately two orders of magnitude higher than observed values. Strontium in the primary coolant circuit of Peach Bottom is attributed to the decay of small amounts of $\mathrm{Kr}$ released from the fuel element.

Verification of FIPER code based upon Peach Bottom Core 1 operation is tentative at best. These predicted releases are based upon experience gained from Core 1 fuel elements in which rigorous mass balances were not obtained. Core 2 fuel elements, which have not been analyzed, operated for about twice the length of time as Core 1 elements and at much higher temperatures. A rigorous confirmation of fission product design product design methods await Peach Bottom HTGR decommissioning studies. 


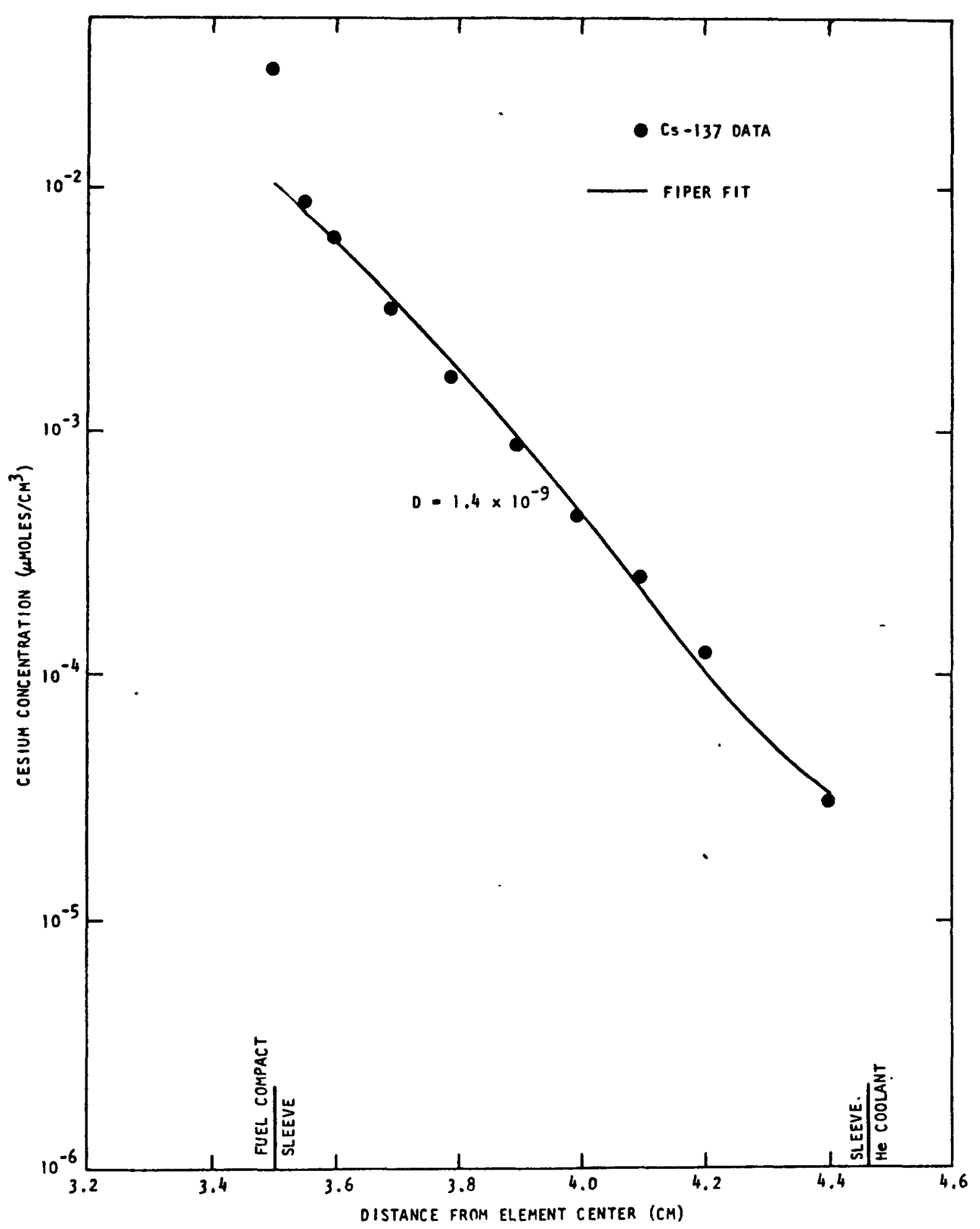

Fiq. 6.1. FIPER code fit to cesium concentration profiles data of Peach Bottom Core 1, 013-05 fuel element, sleeve position 9. 


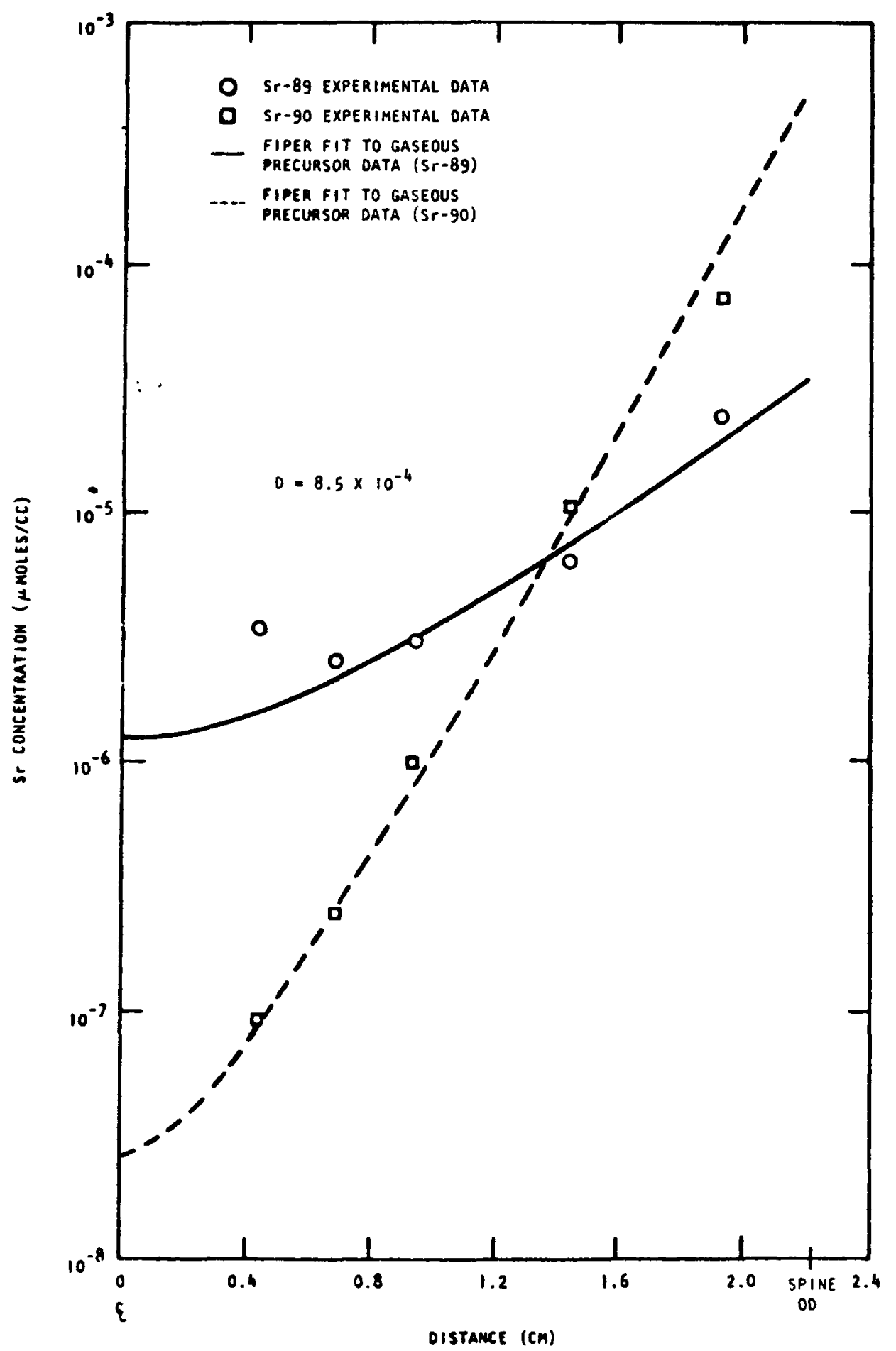

Fig. 6.2. FIPER code fit to strontium concentration profiles data of Peach Bottom Core 1, 013-05 fuel element, spine position 9 . 


\subsection{PAD}

The validity of the PAD code has been tested by comparison with experimental plateout profiles measured in the GA and BMI deposition loops and in the Dragon and Peach Bottom HTGRs. Results and conclusions of these integral tests are presented in detail in Ref. 21.

\subsubsection{GA Deposition Loop}

The GA deposition loop was designed to study the deposition and reentrainment of cesium, strontium, and iodine and to test the validity of the PAD code. In each case, plateout profiles were predicted with the code for comparison with the as-measured profiles. Results for 2 of 5 loops are shown in Figs. 6.3 and 6.4 , respectively.

Inspection of Fig. 6.3 shows large discrepancies between the predicted and measured profiles for Loop No. 1. The slope of the experimental profile over the first $50 \mathrm{~cm}$ of tubing is much steeper than predicted, yet at other locations (see dotted lines) the slope is about as expected. Far more distressing, however, is the large but unpredicted increase of plateout levels in the chill section. The cause of this increase is unknown as is the reason for the abrupt decrease in activity, which occurs about halfway through the chill. Since the as-measured surface temperatures are too low $\left(\leq 260^{\circ} \mathrm{C}\right)$ to yield sorption effects with the reference isotherm, the predicted profile shows a monotonic decrease from the source.

The 1-131 plateout profile obtained in Loop 3 is in good agreement with the predicted profile. The iodine profile is most interesting when compared to the cesium profile from Loop 1. The operating conditions of these two loops were quite similar, although Loop 1 did have a $20 \%$ higher mass flow rate and slightly lower surface temperature $\left(20\right.$ to $\left.60^{\circ} \mathrm{C}\right)$. The effect of flow disturbers (particularly at the entrance contraction and 90-deg bend at the apex) seems much less pronounced on the iodine profile compared to the cesium profile. But more surprising, the chill section seems to have had much less effect on iodine than on cesium, a strange effect indeed 


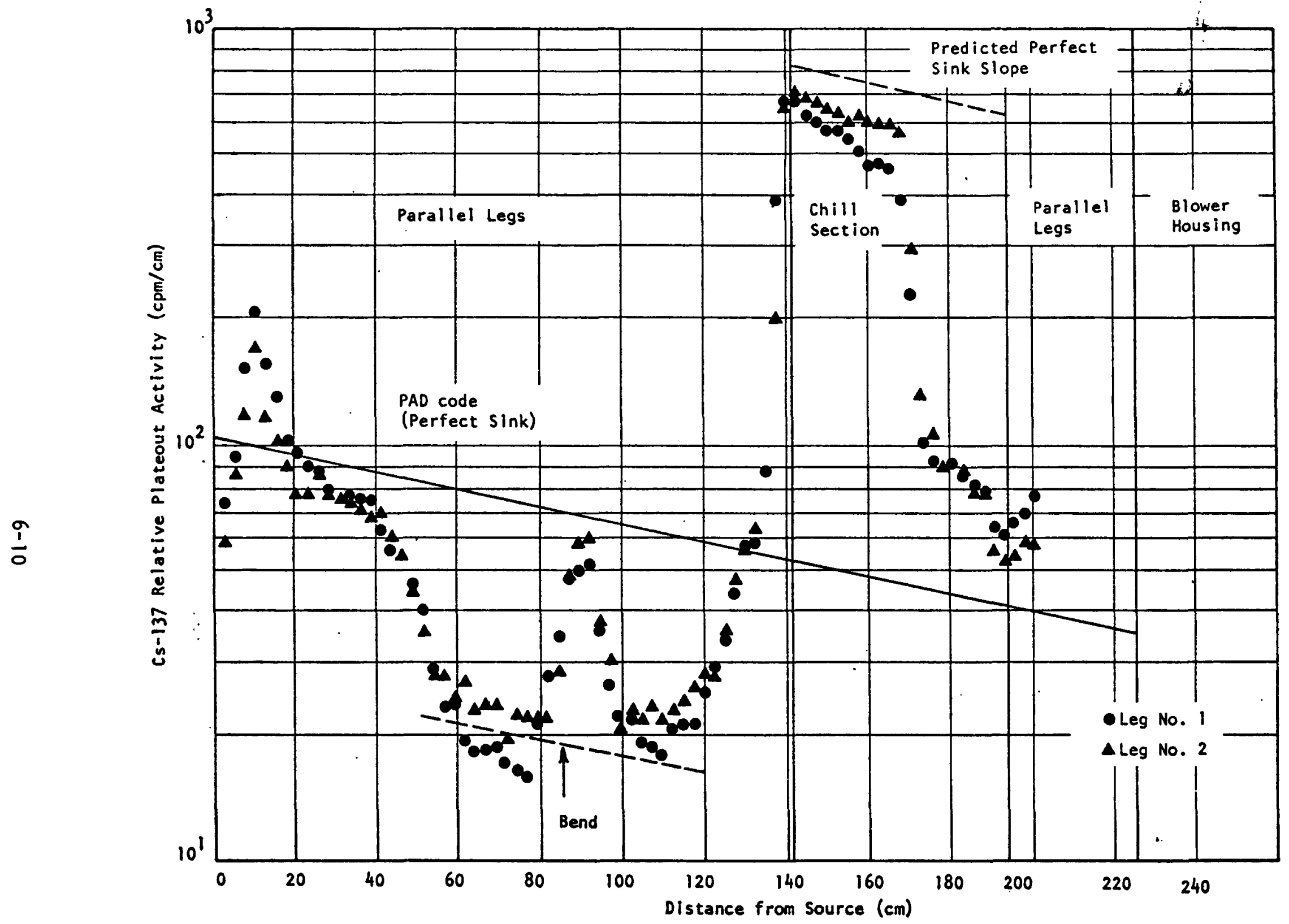

Fig. 6.3. PAD Code Simulation of Loop \#1 (Cs-137) Plateout) 


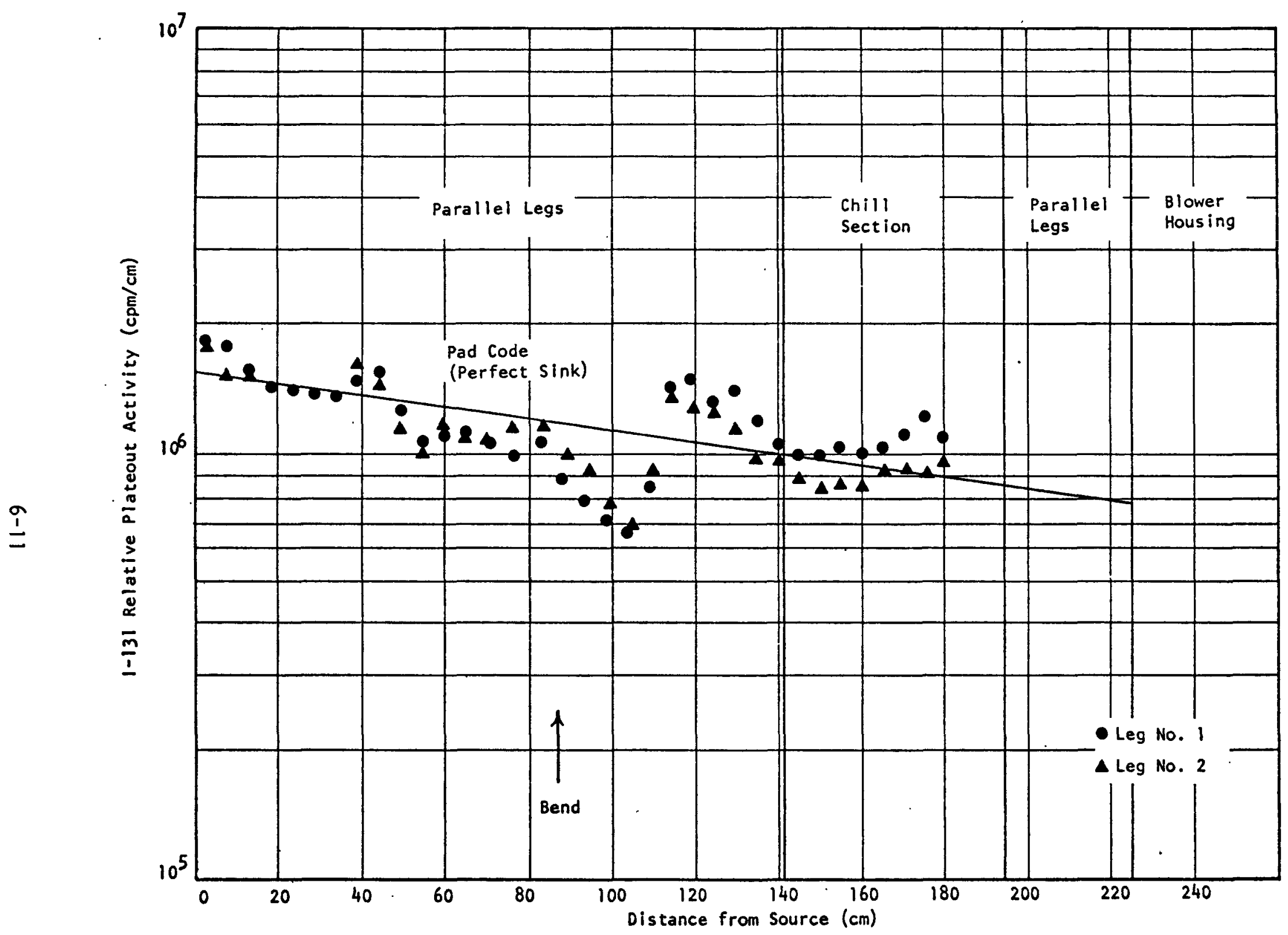

Fig. 6.4. PAD Code Simulation of Loop \#3 (1-131) Plateout) 
since iodine is more volatile. Taken as a whole, the code fit of the iodine data is quite good; however, the cesium profile in Loop No. 1 is simply not understood.

\subsubsection{BMI Deposition Loop}

The Battelle Memorial Institute out-of-pile deposition loop study $(22,23)$ was one of the first efforts to obtain definitive plateout data. The apparatus consisted of metallic vapor source, high- and low-temperature isothermal tube section, heat exchanger, circulator and gas heaters. Specimens of irradiated fuel particles were heated to $1800^{\circ} \mathrm{F}$ for $67 \mathrm{hrs}$, during which time helium coolant maintained at 2300 psi were circulated through the heat exchanger with input and exit temperatures of $635^{\circ} \mathrm{C}$ and $349^{\circ} \mathrm{C}$.

Plateout distributions for Ce-144, Ce-141 + Ce-144, Zr-95, Ru-103, Cs-137, Te-129, and 1-131 were reported. An example profile for Cs-137 is reproduced in Fig. 6.5. The thin solid lines in this figure represents the BMI researchers' attempt to correlate the data, and the other curves represent Hanson's attempt. (21)

Preliminary parameter studies were performed with the PAD code using reference physical data as a base. Good qualitative agreement was realized when treating the surface as a perfect sink for $\mathrm{Ce}-144, \mathrm{Zr}-95, \mathrm{Ru}-103$, and Te-129 and when employing extrapolated adsorption isotherms for $1-131$ and Cs-137. To obtain the proper cesium distribution, it was necessary to presume that the S\$316 surfaces of the BMI loop had a cesium sorptivity I/333 that of oxidized S\$304 (for which laboratory sorption data are available). Furthermore, it was necessary to assume that the iodine sorptivity of SS316 was $1 / 10$ that of $1 \% \mathrm{Cr}, 1 / 4 \%$ Mo chromalloy steel.

While the agreement between predicted and measured profiles was qualitatively good when using reference input data, the slopes of the predicted profiles are consistently steeper than that of the observed ones by 60 to $80 \%$. Under perfect sink conditions, the slope of the theoretical profile on 




Fig. 6.5. Distribution of $\mathrm{Cs}-137$ Activity in Portions of BMI Loop 
semi-log coordinates is $-4 k / v d$ where $k$ is the mass transfer coefficient, $V$ the velocity, and $d$ the inside diameter. $(22,24,25)$ Thus, the reasonable conclusions is that the mass transfer coefficient has been overestimated.

\subsubsection{Dragon HTR}

Considerable data have been obtained by examination of the primary circuit of the Dragon HTR, including disassembly of primary heat exchangers to measure the plateout distributions of such important fission products as Cs-137 and 1-131 (see, for example, Refs. 26 and 27).

About $200 \mathrm{mCi}$ of $\mathrm{Cs}-137$ were estimated to have been released into the Dragon primary circuit during fuel charges 1 and 11 , and about $90 \%$ of the total was released from fuel charge 11 . Furthermore, it was observed that less than $2 \%$ resulted from decay of $\mathrm{Xe}-137$. Therefore, for simplicity, it was assumed in this validation test that all $220 \mathrm{mCi}$ of $\mathrm{Cs}-137$ were released under fuel charge 11 conditions and that all plateout cesium had been directly released (i.e., the noble gas decay route was ignored). With these assumptions and time-average $R / B s$ a series of $P A D$ validation runs were made. Four cases were considered: (1) perfect sink conditions throughout the circuit, (2) cesium/graphite and cesium/oxidized SS304 sorptivities, (3) case 2 with metal sorptivity reduced by a factor of 33 , and (4) case 2 with metal sorptivity reduced by a factor of 333 . The predicted results are in excellent agreement with the data; in fact, the discrepancies are generally within the estimated experimental error (factor of 2 in the heat exchangers and factor of 5 in the circulator and heat exchanger housing). It should be noted, however, that Dragon heat exchanger conditions are not representative of HTGR conditions i.e., temperatures, concentration of fission products, materials, etc.

\subsubsection{Peach Bottom HTGR}

No major components of the Peach Bottom HTGR primary circuit have had to be removed during its operational life with the exception of some Core 1 fuel elements. Therefore no definitive information regarding the plateout 
activity distribution presently exists. However, several external gamma surveys have been made of accessible ducts by ORNL personnel. (11) This information, together with some diffusion probe measurements, provide a tentative estimate of the plateout inventory.

Because of the indirect nature of the measurement, ambiguity exists regarding not only the relative plateout distribution, but also the total plateout inventory of important nuclides. While several different estimates of the Cs-137 inventory have been made, the actual inventory is probably between 50 and $100 \mathrm{Ci}$ of $\mathrm{Cs}-137$.

Results for the $100 \mathrm{Ci}$ inventory are summarized in Fig. 6.6. The distribution of Cs-137 after Core 1 was predicted for total releases of 10 and $100 \mathrm{Ci}$ (21) For each plateout level, three sampler cases were considered in the validation exercise: (1) perfect sink conditions throughout circuit, (2) cesium/graphite and cesium/steel sorption in the hot leg (with a metal sorptivity three times that of oxidized 55304 stainless steel), and (3) case 2 with the metal sorptivity reduced by a factor of 100.

From inspection of Fig. 6.6, it is observed that a reasonably good fit of the $\mathrm{Cs}_{\mathrm{S}} 137$ data is obtained fo- a total release of $100 \mathrm{Ci}$. Upon assumption of isotopic scrambling, the $\mathrm{Cs}-134$ data are compared to the $\mathrm{Cs}_{5}-137$ prediction by direct scaling. However, when contrasting the cesium data with that of $\mathrm{Ce}-144$, there is evidence of cesium sorption effects in the hot ducts. The implications are compromised by the uncertainties in the cesium inventories, the role of minute quantities of fuel dust, (28) and the effect of Core 2 operation. 


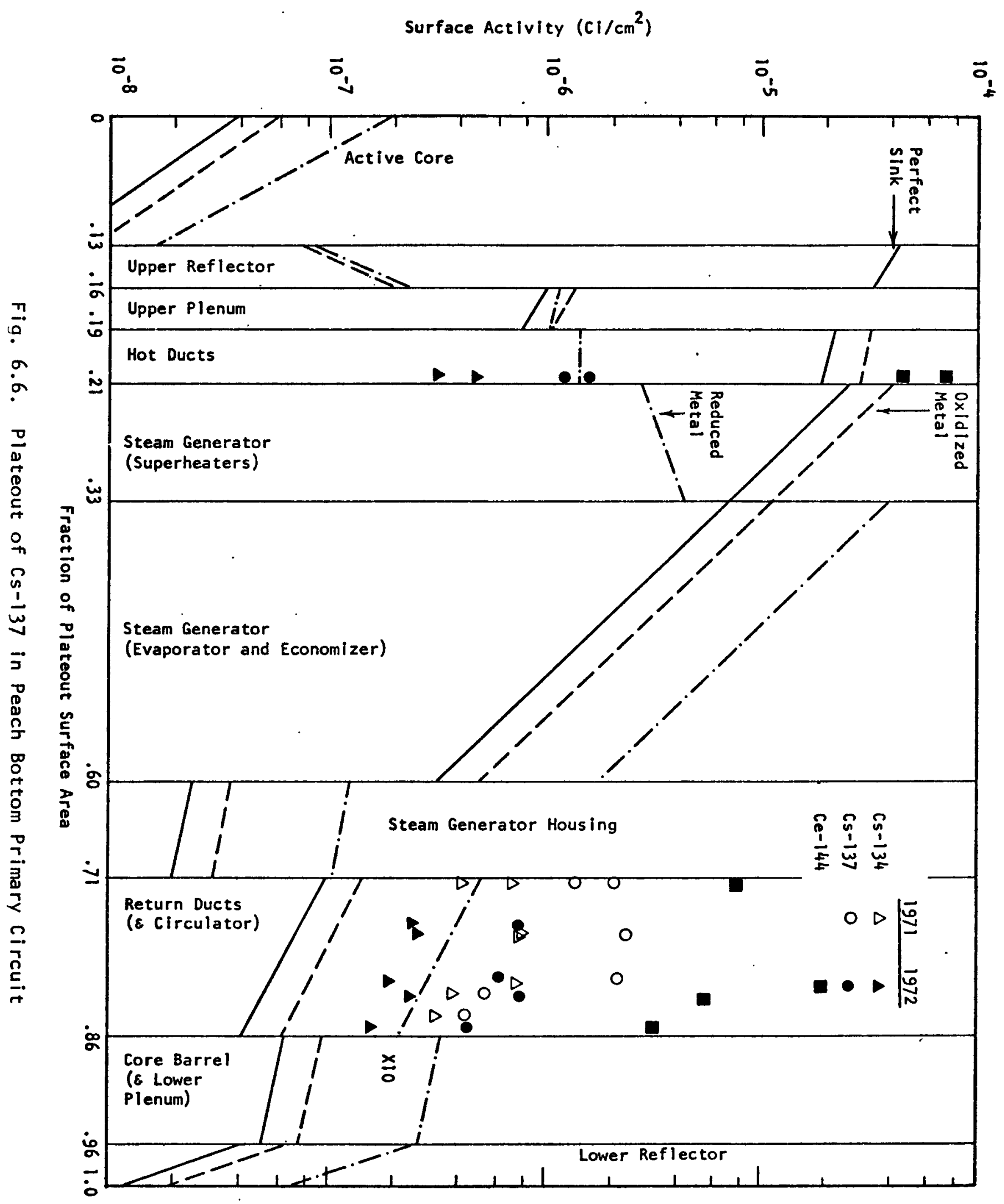




\section{VALIDATION PROGRAM SCHEDULE}

A summary of validation experiments, principal milestones and anticipated schedules is included in Table 7.1 .

The principal objective of this task is to validate fission product design methods prior to issuance of Delmarva 770 MW(e) HTGR FSAR, scheduled for Jan. 1978. Thus, the bulk of this work must be completed by end of fiscal year (FY) 1978. Further work will be carried on in FY 1979-80 including continuing Fort St. Vrain surveillance and additional capsule studies, but at a lower anticipated level. Since the objective of this task is to systematically evaluate and analyze data which will be available for programs already established, this validation task and program plan does not propose new experimental programs at this time. The status of fission product data, and hence the need for new programs and directions is presently being studied. As a result of this study, new testing programs or modification of planned or existing programs may be recommended which will require additional analytical effort.

Much of the verification data is acquired by organizations other than GA. Specifically, virtually all loop measurements are made by CEA in France. Indeed, independent code verification efforts are being pursued by Dragon Project, HRB, and CEA, as well as GA. In the United States, data for all Peach Bottom driver fuel elements used for code validation will be obtained by ORNL. Fort St. Vrain operational data will, of course, be obtained at Fort St. Vrain using PSC instrumentation and equipment.

It should be noted that the proposed schedules are subject to later revision, dependent upon manpower and approved funding levels. Current reviews of the scheduling and funding can be found in the HTGR National Chemistry Program Plan. 
TABLE 7.1

Proposed Fission Product Code Validation Milestones

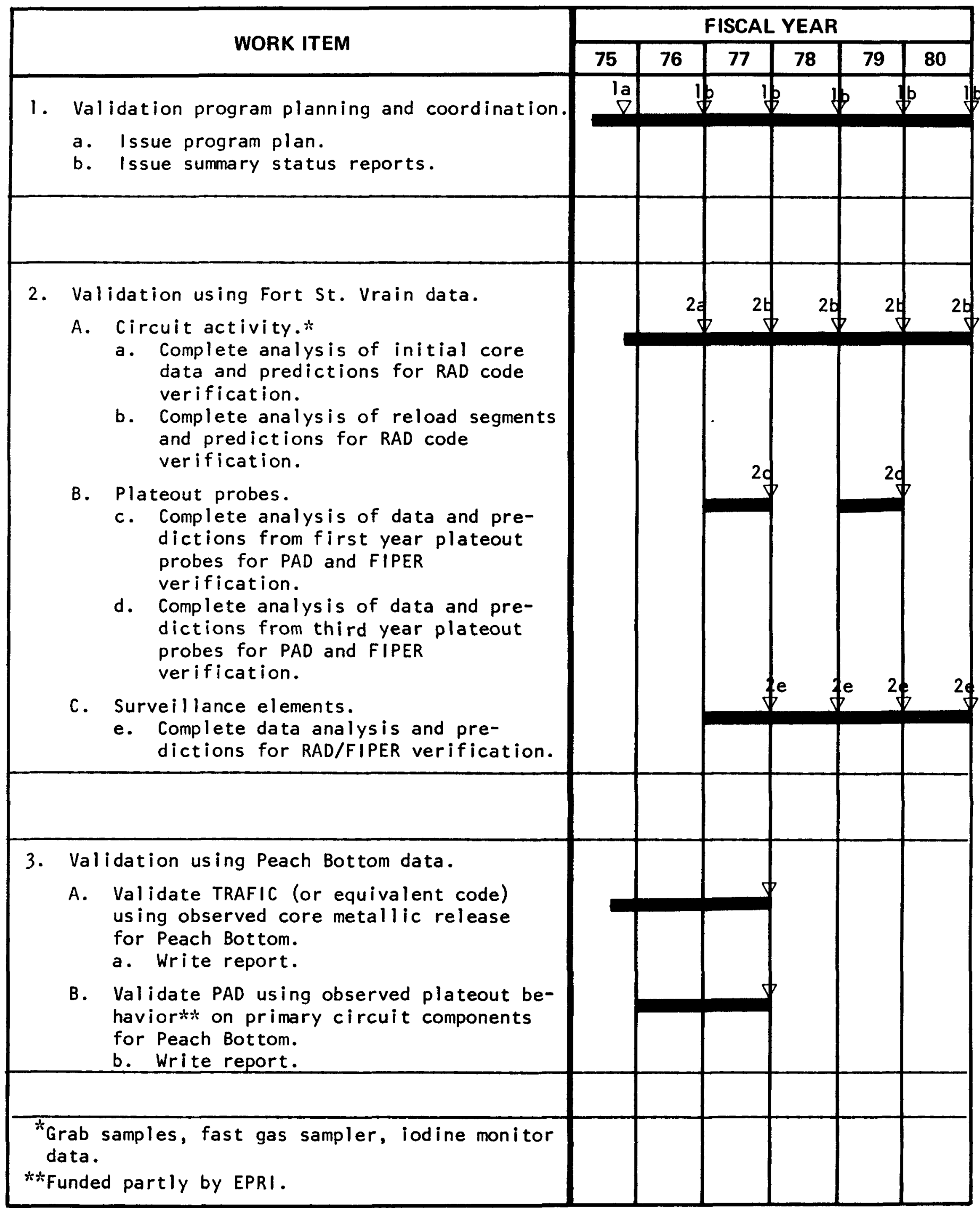




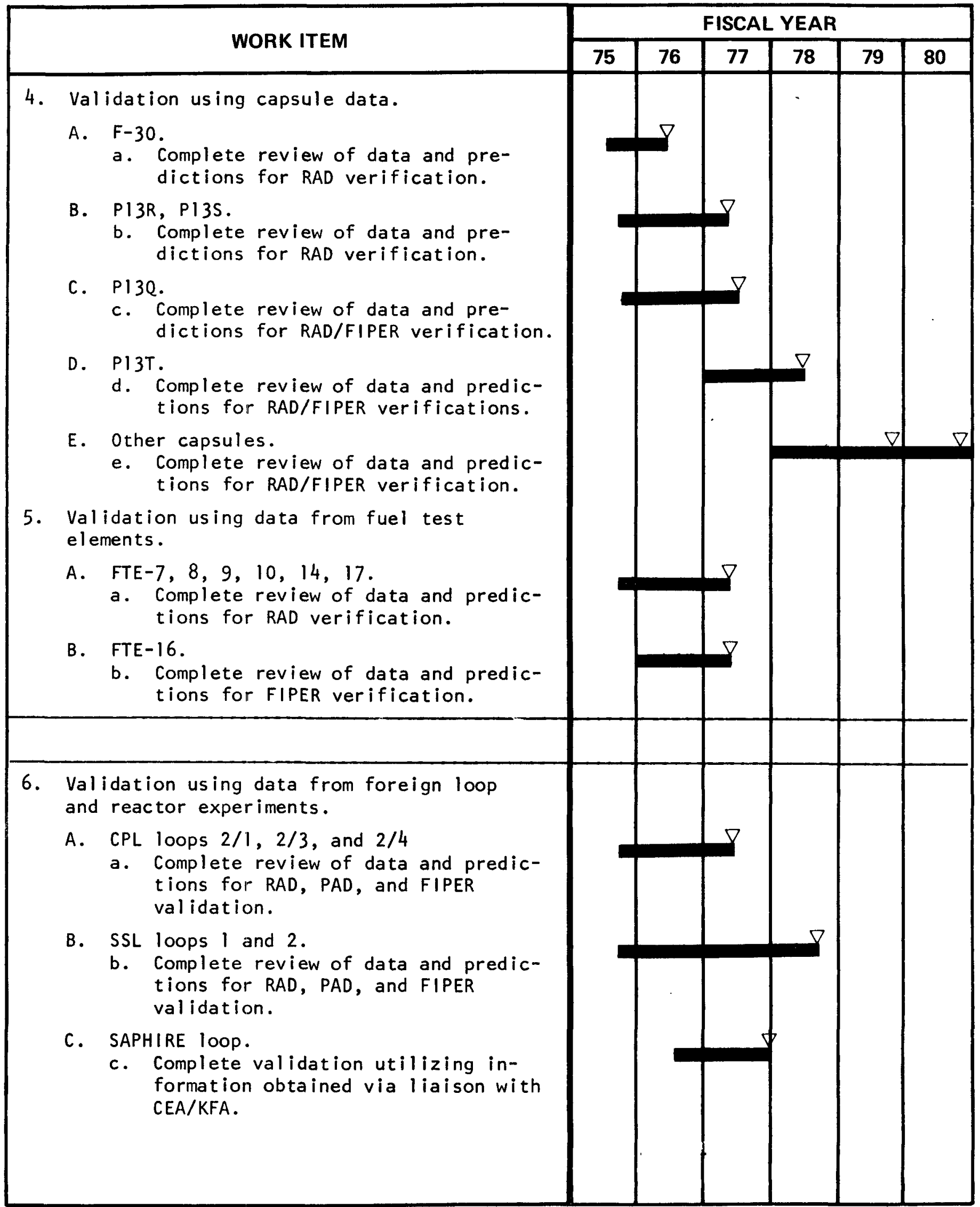


TABLE 7.1 (continued)

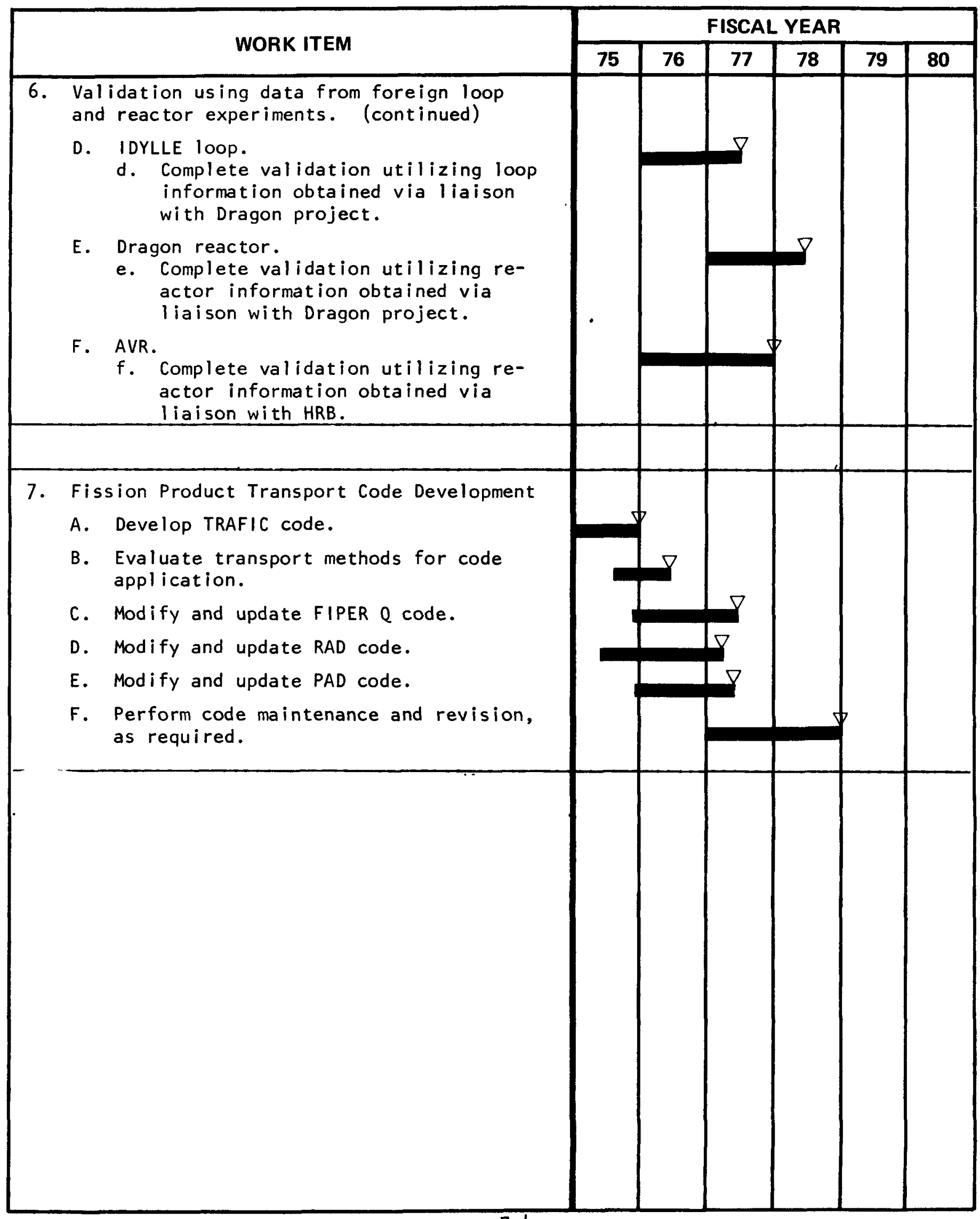




\section{REFERENCES}

1. Vanslager, F.E., "RAD 2, A Computer Program for Calculating Fission Product Radioactivities", USAEC Report GAMD-6519, General Dynamics, General Atomic Division, July 28, 1965.

2. Haire, M.J., and D. W. McEachern, "Gaseous Radioactivity Levels in the Primary Coolant of an HTGR", General Atomic Report GA-Al2946 (GA-LTR-14) Oct. 1, 1974.

3. Forutanpour, B., and B. Roos, "FIPER X, a FORTRAN V Program for the Solution of One-Dimensional Linear and Non-1 inear Diffusion Problems", USAEC Report GA-9904, Gulf General Atomic, Sept., 1969.

4. 'HTGR Base Program Quarterly Progress Report for The Period Ending August 31, 1974", USAEC Report GA-A13126, General Atomic Co., Sept. 30,1974 .

5. Vanslager, F.E., and Mears, L.D., "PAD: A Computer Code for Calculating the Plateout Activity Distribution in a Reactor Circuit", USAEC Report GA-10460, Gulf General Atomic, January, 1971.

6. Walker, R. E., and T. A. Johnston, "Fort St. Vrain Nuclear Power Station", Nuclear Engineering Intl., Vol. 14, No. 063, Dec., 1969.

7. Peach Bottom Atomic Power Station, Final Hazards Summary Report, Philadelphia Electric Company.

8. "Planning Guide for HTGR Safety and Safety-related Research and Development", USAEC Report ORNL-4968, Oak Ridge National Laboratory, May, 1974, Appendix B.

9. Haire, M.J., and L.R. Zumwalt, "Cesium Diffusion Coefficients and other Results from the Analysis of Peach Bottom D13-05 Fuel Element Activity Profiles", USAEC Report Gulf-GA-A12492, Gulf General Atomic, July 26, 1973.

10. Burnette, R.D., W. E. Bell, and N. L. Baldwin, 'Fission Product Retention Characteristics of HTGR Fuel", Proceedings of the International Conference on Nuclear Fuel Performance, Paper 16, British Nuclear Energy Society, London, October 15-19, 1973.

11. de Nordwall, H.J., F. F. Dyer, J. O. Kolb, and W. J. Martin, "An Interim Report on Fission Product Release During Operation of the Second Peach Bottom Core", Proceedings of the International Conference on Nuclear Fuel Performance, Paper 18, British Nuclear Energy Society, London, October 15-19, 1973. 
12. Smith, C.L., "Fuel Particle Behavior under Normal and Transient Conditions", USAEC Report GA-A12971 (GA-LTR-15), General Atomic Co., Oct. 1, 1974.

13. Muller, H.W., C. B. von der Decken, U. Hennings, and W. Stürner, "The AVR Pebble Bed Reactor", J. Brit. Nucl. Energy Soc., (1) 1966.

14. Chandra, D., "Specification for CPL 2/1 Pegase Loop Experiment", U0923 General Atomic Co., Feb. 18, 1974.

15. Stula, R.T., and C.F. Wallroth, "SPITFIRE SSLI Experiment", U0954, March 29, 1974.

16. 'HTGR Base Program Quarterly Progress Report for Period Ending Nov. 30 , 1973", USAEC Report Gulf GA-A12818, Gulf General Atomic, Dec. 28, 1973.

17. Wallroth, C.F., N.L. Baldwin, C.B. Scott, and L.R. Zumwalt, "Postirradiation Examination of Peach Bottom Fuel Test Element FTE-3", USAEC Report GA-A13004, General Atomic Co., Aug. 15, 1974.

18. Chandra, D. and J. H. Norman, "Diffusion of Cesium Through Graphite", USAEC Report GA-A13019, General Atomic Co., to be published.

19. "HTGR Fuels and Core Development Program Quarterly Progress Report for the Period Ending Aug. 30, 1975". USAEC Report GA-A13126, General Atomic Co., Sept. 30, 1974.

20. de Nordwall, H.J., V.H. Pierce and L. R. Zumwalt, "Experimental Test of The FREVAP- 8 code for Calculating Metal Fission Product Release from HTGR Fuel Elements", USAEC Report GA-9093, Gulf General Atomic, Nov. I, 1968.

21. Hanson, D.L., "Results of the General Atomic Deposition Loop Program", USAEC Report GA-A13140, General Atomic Co., to be published.

22. Raines, G.E., A. Abriss, D.L. Morrison, and R.A. Ewing, "Experimental and Theoretical Studies of Fission-Product Deposition in Flowing Helium", USAEC Report BMI-1688, Battelle Memorial Institute, August 4, 1964.

23. Raines, G.E., A. Abriss, D.L. Morrison, and R.A. Ewing, "Studies of Fission-Product Deposition in Out-of-Pile Loops", CONF-650407 (Vol. 2), International Symposium on Fission Product Release and Transport Under Accident Conditions, Oak Ridge National Laboratory, April 30, 1965.

24. Ozisik, M.N., "An Analytical Model for Fission Transport and Deposition from Gas Streams", USAEC Report ORNL-3370, Oak Ridge National Laboratory, July, 1963.

25. Kress, T.S., and F.H. Neill, "A Model for Transport and Deposition under Isothermal Condtions", USAEC Report ORNL-TM-1274, Oak Ridge National Laboratory, October, 1965. 
26. Brown, P.E., et al., "Measurements of Fission Product Deposition on the Heat Exchangers and Gas Circulators of the Dragon Reactor", Dragon

Project Report DP 564, United Kingdom Atomic Energy Authority, July, 1968.

27. Rowland, P.R., W. E. Browning, and M. Carlyle, "The Behavior of lodine Isotopes in a High Temperature Gas Reactor Coolant Circuit", Dragon Report DP-736, United Kingdom Atomic Energy Authority, November, 1970.

28. Busch, D.D., "Particulate Matter in the Peach Bottom HTGR Primary Coolant System", Gulf General Atomic Report Gulf-GA-B10034, July 7, 1972. 